Cationic nioplexes-in-polysaccharide-based hydrogels as versatile biodegradable hybrid materials to deliver nucleic acids. Grijalvo, S., Alagia, A., Puras, G., Zárate, J., Mayr, J., Pedraz, J. L., Eritja, R., Díaz Díaz, D. J. Mat. Chem. B, 5, 7756-7767 (2017). Doi: $10.1039 / \mathrm{c} 7 \mathrm{tb} 01691 \mathrm{c}$

\title{
Cationic nioplexes-in-polysaccharide-based hydrogels as versatile biodegradable hybrid materials to deliver nucleic acids
}

Santiago Grijalvo, ${ }^{\text {abc }}$ Adele Alagia, ${ }^{\text {b }}$ Gustavo Puras, ${ }^{\text {cd }}$ Jon Zárate, ${ }^{c d}$ Judith Mayr, ${ }^{a}$ José Luis Pedraz, ${ }^{\text {cd }}$ Ramon Eritjabc and David Díaz Díaz ${ }^{*}$ ab

Institute of Organic Chemistry, University of Regensburg, Universitästrasse 31, 93040 Regensburg, Germany. E-mail: David.Diaz@chemie.uni-regensburg.de; Tel: +49 9419434373

${ }^{\mathrm{b}}$ Institute of Advanced Chemistry of Catalonia (IQAC-CSIC), Jordi Girona 18-26, 08034 Barcelona, Spain

'Biomedical Research Networking Centre in Bioengineering, Biomaterials and Nanomedicine (CIBER-BBN), Jordi Girona 18-26, 08034 Barcelona, Spain

${ }^{d}$ NanoBioCel Group, University of the Basque Country (UPV/EHU), Paseo de la Universidad 7, 01006 Vitoria-Gasteiz, Spain

Abstract: Two polysaccharide-based hydrogels made of only kcarrageenan $(4 \% ; w / v)$ or of a mixture of methylcellulose: $k$ carrageenan $(2 \% ; w / v)$ were used to encapsulate cationic nioplexes. These vesicular particles were made of a synthetic aminolipid and polysorbate-80 (Tween-80), as a non-ionic surfactant agent. According to oscillatory rheological measurements, the presence of nioplexes did not compromise the mechanical integrity of the gels. In vitro niosomal release experiments demonstrated the liberation of nioplexes up to $24 \mathrm{~h}$, and the curves were fitted according to Higuchi, Korsmeyer-Peppas and Weibull equation models, which indicated Fickian-diffusion controlled mechanisms. Besides nioplexes, cervical cancer cells were also entrapped within the biohydrogels. Cell release confirmed that these materials did not affect the cell viability, allowing cells to spread and proliferate after $24 \mathrm{~h}$. The applicability of these biocompatible hydrogels was also extended to gene delivery. In this regard, the best silencing activities were found when cationic niosomes were complexed with antisense oligonucleotides in KC hydrogels. Nioplexes were able to release through the hydrogel and promoted silencing of luciferase expression in the presence of serum without using commercially available cationic lipids. Overall, the formation of such hybrid materials by integrating cationic nioplexes within biodegradable hydrogels provides a new perspective for the delivery of macromolecular therapeutics. 


\section{I ntroduction}

Chemical hydrogels are semi-solid materials made of small amounts of hydrophilic polymers dispersed in relatively large amounts of water. ${ }^{1}$ Covalent crosslinking of the polymer chains enables them to swell while maintaining their three dimensional (3D) structure without dissolving. ${ }^{2,3}$

These soft network structures can be prepared from either synthetic (e.g. PEG, PHEMA, PVA) or natural polymers, which have been extensively used in various biomedical applications including, among others, drug delivery and tissue engineering. ${ }^{4,5}$ In the case of natural hydrogels, those made from polysaccharides have special relevance due to their biodegradability, biocompatibility, good mechanical stabilities, injectability, non-immunogenic properties and their abundance in nature. ${ }^{6-15}$ In addition, the existence of multiple functional groups in their structures enables chemical conjugation of different drugs, which results in increasing their hydrophilicity and, consequently, improving their bioavailability and biodistribution properties.

Furthermore, nucleic acid-based therapy has seen a sharp rise in interest in the development of novel antisense and siRNA therapeutics. ${ }^{16,17}$ Despite its therapeutic potential and launching a good number of potential macromolecules for clinical trials, ${ }^{18}$ important issues like improving nucleic acid stability in the bloodstream and cellular uptake remain as the major drawbacks in these kinds of therapies. To overcome these limitations, multiple strategies such as chemical modifications and the use of non-viral carriers has been extensively studied. ${ }^{19}$ Formulation strategies involving liposomes have been widely use to form complexes (lipoplexes) due to the presence of negatively charged nucleic acids and the positive charges of the cationic carrier. Thus, this chargecharge interaction in combination to others parameters have allowed the optimization of formulations that have remarkably improved the nucleic acid delivery for in vitro and in vivo experiments. ${ }^{20-22}$ Furthermore, structurally similar to liposomes, non-ionic surfactant vesicles (niosomes) are vesicular systems in which non-ionic amphiphiles are able to self-assemble in aqueous solution giving rise to closed-bilayer vesicles. ${ }^{23}$ In general, the remarkable interest generated by niosomes as drug delivery systems ${ }^{23}$ and non-viral carriers for nucleic acids, ${ }^{24-27}$ relies on their chemical stability, uniform content and ease of storing.

The possibility to entrap a good number of cargoes (e.g. small molecule drugs, ${ }^{28,29}$ nanoparticles, ${ }^{30}$ liposomes/niosomes ${ }^{14}$ ) within hydrogels represents an interesting strategy to be able to control the release of a certain therapeutic drug and consequently enhance its therapeutic effect. ${ }^{29,31-35}$ In this work, we have evaluated the ability of k-carrageenan $(\mathrm{KC})$ and a $1: 1$ mixture of methylcellulose : $\mathrm{k}$ - 
carrageenan ( $\mathrm{MC}$ : $\mathrm{KC}$ ) based hydrogels to entrap niosomal formulations (i.e. lipid-based cationic nioplexes) (Fig. 1). The main reasons for the selection of the KC and MC: KC gels are their wellestablished biocompatibility and appropriateness for applications involving cells. ${ }^{6-15}$

In vitro controlled release experiments of such niosomal formulations containing a fluorescently labeled oligonucleotide (FITCODN) were evaluated. Higuchi, Korsmeyer-Peppas and Weibull equation models were used to fit the niosomal release data and analyze both the mechanism and diffusion kinetic parameters. Moreover, the applicability of macroscopic polysaccharide-based hydrogels was first investigated by encapsulating living cells within polymer matrices in order to evaluate their effect on cellular viability. Furthermore, KC and MC: KC hybrid materials containing cationic nioplexes based on antisense oligonucleotides and GFP plasmid (pGFP) were also investigated in cell culture by studying their cytotoxicity, in vitro gene transfer properties and cellular uptake studies. To the best of our knowledge, the use of biohydrogels for the encapsulation and controlled release of nucleic acid formulations are scarcely represented in the literature. ${ }^{36-39}$ It should be emphasized that this work represents a significant progress in comparison to our previous study ${ }^{38}$ using a hydrogel based on low-molecular-weight gelator (Fmoc-Phe) where biocompatibility issues and lack of luciferase inhibition prevented the measurement of antisense activity.

\section{Experimental section}

\section{Materials}

All reagents employed were used as received without further purification. Polysorbate-80 (Tween-80), k-carrageenan (KC), methylcellulose (MC), 3-(4,5-dimethylthiazol-2-yl)-2,5diphenyltetrazolium bromide (MTT reagent), SYBR-green I nucleic acid gel stain and a phosphorothioate oligonucleotide of sequence (5'-CGT TTC CTT TGT TCT GGA-3'; Luc) were purchased from SigmaAldrich (St. Louis, Missouri, USA). 5'-Fluorescein-CE phosphoramidite (6-FAM) was purchased from Link Technologies (Lanarkshire, Scotland). A fluorescently labeled oligodeoxynucleotide sequence (5'FITC-CGG AGG TAC ATT CGA CTT GA-3'; FITC-ODN) ${ }^{40}$ and a scrambled phosphorothioate oligonucleotide sequence (5'-CTG TCT GAC GTT CTT TGT-3'; Scr) were synthesized in a DNA/RNA synthesizer $A B I 3400$ and purified according to DMT off-based protocols with a semi-preparative HPLC. 6-FAM was automatically coupled at the 5'-termini via phosphoramidite chemistry. Standard phosphoramidites and ancillary reagents used for the synthesis of FITC-ODN and Scr oligonucleotides were purchased from Link Technologies (Lanarkshire, Scotland). Plasmid PMax-GFP (pGFP) was purchased from Lonza (Allendale, NJ, USA). Cationic lipid_1 was 
purchased from Sapala Organics Privated Ltd (Telengana St., India). Cationic niosomes based on lipid_1 were prepared as previously

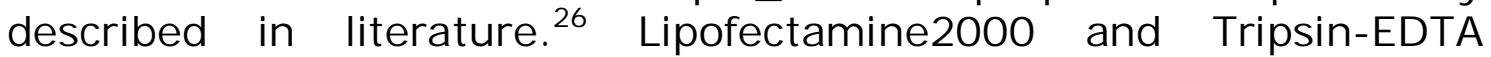
$(0.25 \%)$, phenol red were purchased from ThermoFisher Scientific (Waltham, MA, USA). Dulbecco's Modified Eagle's Medium (DMEM) was supplemented with $10 \%$ heat-inactive fetal serum bovine (FBS). DMEM, PBS buffer, OptiMEM and distilled water (DNAse/RNAse free) were purchased from Gibco (Waltham, Massachussets, USA). Alternatively, nuclease-free water was also prepared by using $0.1 \%$ of diethylpyrocarbonate (DEPC) to ensure the removal of RNase contamination, autoclaved and filtered before using. Dual-luciferase reporter assay system was purchased from Promega (Madison, Wisconsin, USA). Qiagen Giga plasmid purification kit was purchased from Qiagen.

\section{General procedure for the preparation of FITC-ODN, Luc and pGFP forming complexes}

Cationic niosomes in HEPES buffer $(20 \mathrm{mM}$, pH 7.4) were combined with a fixed concentration of FITC-ODN, Luc or Scr oligonucleotides at N/P ratio of 14 in an appropriate volume. In the case of pGFP $(2 \mu \mathrm{g})$, cationic niosomes were combined at 30/1 (w/w) mass ratio. Mixtures were vortexed for $5 \mathrm{~s}$, sonicated for $20 \mathrm{~s}$ and incubated at $37 \stackrel{\circ}{\circ}$ for $30 \mathrm{~min}$ in order to favor electrostatic interactions between negatively charged nucleic acids and the niosomal formulation containing the cationic lipid_1. Finally, cationic nioplexes were obtained and ready for use. TEM microscopy was carried out to visualize and characterize these complexes (ESI, $\dagger$ Fig. S1).

\section{Electrophoretic mobility shift assay (EMSA)}

FITC-ODN $(0.25 \mu \mathrm{M})$ and growing concentrations of cationic

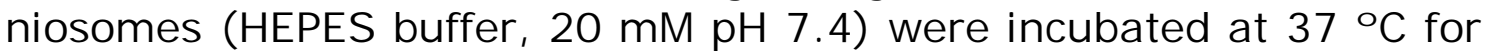
30 min (total volume $=25 \mu \mathrm{L}$ ). The obtained nioplexes were analyzed by native polyacrylamide gel electrophoresis (PAGE) (20\%) at $150 \mathrm{~V}$ and $25 \stackrel{\circ}{\circ}$ for $6 \mathrm{~h}$ in $1 \times$ TBE as running buffer. Glycerol (50\%) in $1 \times$ TBE was used as a loading buffer. Pre-formed nioplexes were analyzed at several N/P ratios that ranged from 0.5 to 18 . Finally, PAGE gel was immersed in $1 \times$ TBE buffer $(200 \mu \mathrm{L})$ and stained with SYBR-green I nucleic acid gel stain $(20 \mu \mathrm{L}$ ) (15 min shaking at room temperature (RT)). Pictures were taken using IR-LAS-1000 Lite v1.2 and Fujifilm LAS-1000 Intelligent Dark Box II instruments. 
A

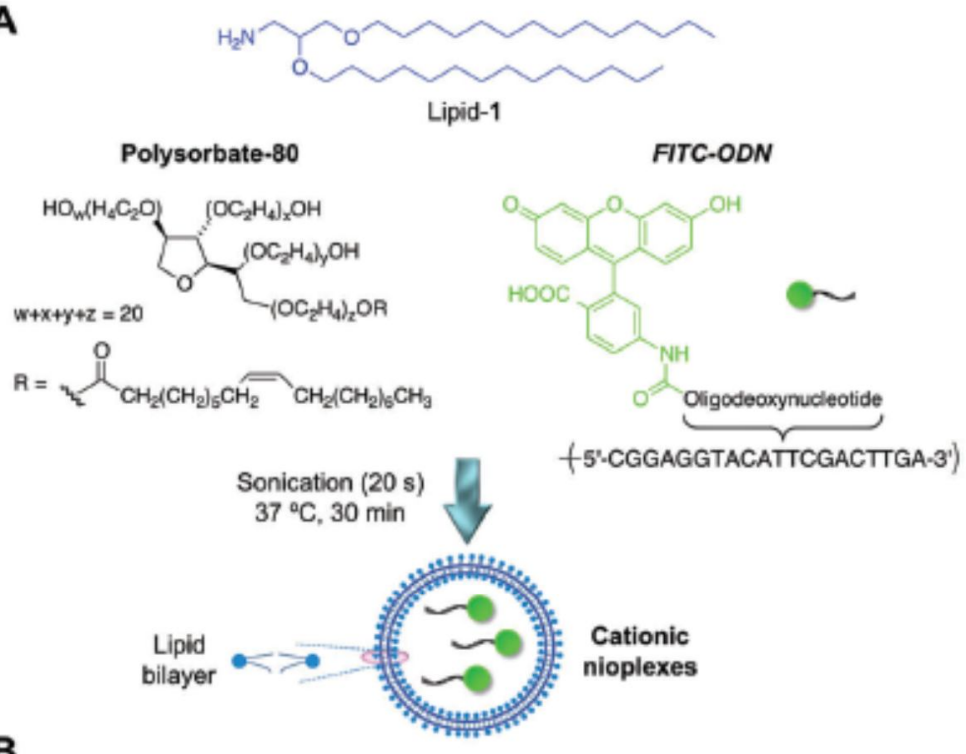

B

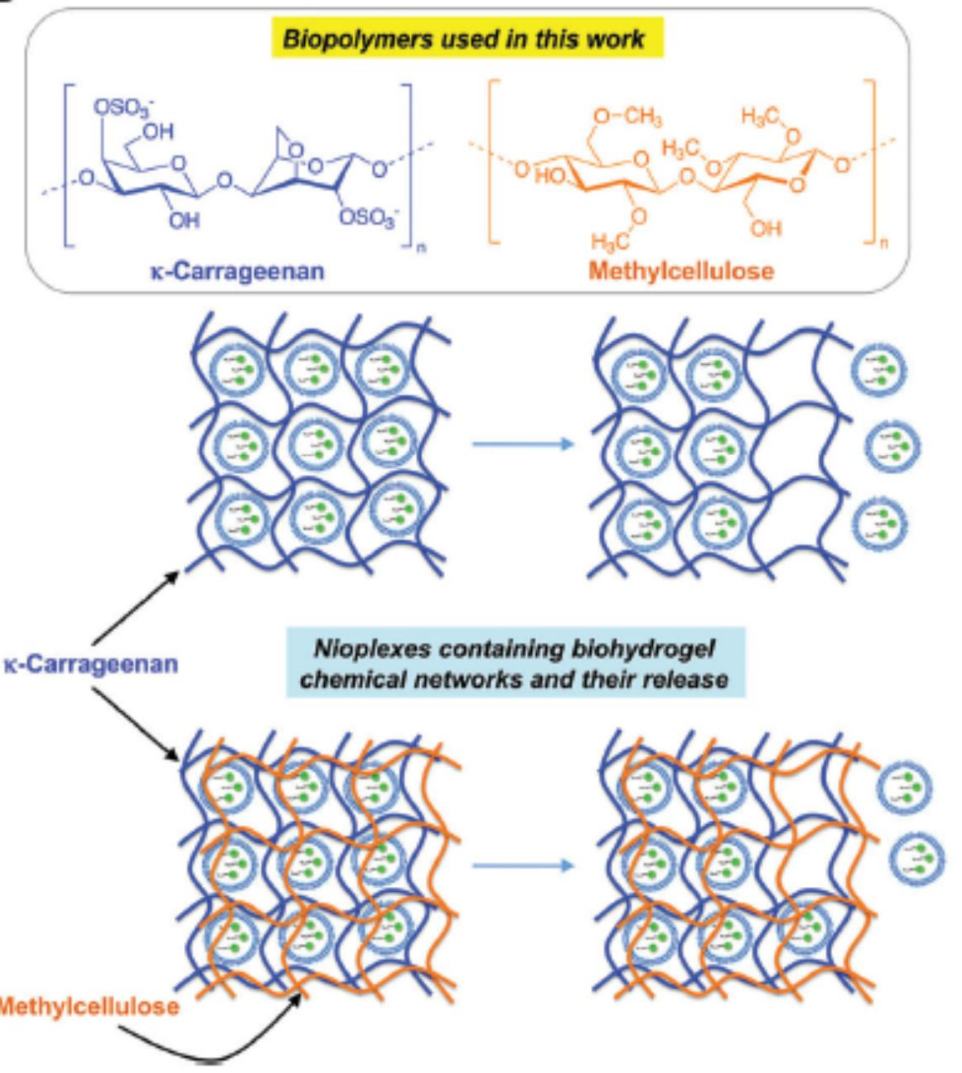

Fig. 1 (A) General synthesis of cationic nioplexes based on lipid- 1 containing FITC-ODN. (B) Cationic nioplexes were entrapped in KCor MC:KC-based hydrogels (Hydrogel_1 and Hydrogel_2, respectively). FITC-ODN, LuC and pGFP were used for preparing different cationic nioplexes used in this work.

General procedure for the preparation of polysaccharidebased hydrogels

Control hydrogels without cationic nioplexes made of KC (i.e., Hydrogel_1; 4\%; w/v) and 1 : 1 mixture of MC: KC (Hydrogel_2; 2\% 
each; w/v) (in total 4 wt\% of biopolymers) were prepared. The corresponding polysaccharides were stirred in HEPES buffer $(20 \mathrm{mM}$, $\mathrm{pH}$ 7.4) (800 $\mu \mathrm{L})$ at $85 \stackrel{\circ}{\mathrm{C}}$ for $30-45 \mathrm{~min}$, and subsequent cooling of the obtained solutions to RT. In the case of Hydrogel_1; 1 M KCl (200 $\mu L)$ was added to the solution made of $K C$. So-formed native Hydrogel_1 and Hydrogel_ 2 were stored at 4 으 until further usage as controls. Note: we have not observed so far significant differences in the thermo-mechanical stability of different bulk biohydrogels when they have been prepared at room temperature (data not shown).

For the preparation of cationic nioplexes-in-polysaccharide based hydrogels; $500 \mu \mathrm{L}$ of cationic lipid/FITC-ODN (1), cationic lipid/Luc (2) and cationic lipid/Scr (3) complexes, which were obtained as described before, were mixed at RT for $10 \mathrm{~min}$ with the appropriate amount of polymers (KC or MC:KC). The mixtures were slightly vortexed and sonicated ( $5 \mathrm{~s}$ ) to afford the desired hydrogels containing cationic nioplexes (Hydrogel_3-8). Several concentrations of FITC-ODN (0.08-0.5 $\mu \mathrm{M})$, Luc and Scr oligonucleotides (0.06-0.3 $\mu \mathrm{M})$ were used to form the corresponding nioplexes. Hydrogel materials were stored at 4 으 until further usage. Encapsulation efficiency (EE) of cationic nioplexes within polysaccharide-based hydrogels was calculated by the ratio between the FITC-ODN remaining mass in the receptor phase at $t=0$ and the initial amount of FITC-ODN oligonucleotide according to eqn (1).

$$
\mathrm{EE}(\%)=\frac{\text { mass }(\text { niosomal FITC }- \text { ODN } \text { in the receptor phase })}{\text { mass }(\text { initial amount of niosomal FITC }- \text { ODN })} \times 100
$$

\section{Rheology of polysaccharide-based hydrogels}

Oscillatory rheology measurements were performed at $251 \mathrm{C}$ on a AR2000 Advanced stress-controlled rheometer (TA Instruments) with a plate-plate geometry (20 $\mathrm{mm} \varnothing ; 0.5 \mathrm{~mm}$ gap) and equipped with a Julabo $\mathrm{C}$ cooling system. Hydrogels ( $500 \mu \mathrm{L}$ ) were prepared 24 $\mathrm{h}$ prior measurements and stored at $4 \stackrel{\circ}{\mathrm{O}} \mathrm{C}$. Native hydrogels made of KC and MC:KC (Hydrogel_ 1 and Hydrogel_2, respectively) were used as controls. To evaluate the effect of cationic nioplexes in the gelation process, niosomal formulations were embedded into the two native hydrogels (Hydrogel_3 and Hydrogel_4, respectively). The storage modulus ( $\left.G^{\prime}\right)$ and the loss modulus ( $\left.G^{\prime \prime}\right)$ of the hydrogels were analyzed performing frequency sweep (DFS), dynamic strain sweep (DSS) and dynamic time sweep (DTS) experiments. DFS showed the variation of $G^{\prime}$ and $G^{\prime \prime}$ with frequency (from 0.1 to $10 \mathrm{~Hz}$ at $0.1 \%$ strain) at an angular frequency of $3 \mathrm{rad} \mathrm{s}^{-1}$ and low shear stress to determine the linear viscoelastic regime (LVR). DSS measurements showed the variation of $G^{\prime}$ and G" with strain (from 0.01 to $100 \%$ ) at a constant frequency ( $1 \mathrm{~Hz}$ ) to determine the strain at break. Finally, 
DTS measurements within the LVR showed the evolution of G' and G" upon aging.

\section{Standard fluorescence curve}

Fluorescence measurements were recorded on a Fluoromax-4 spectrofluorometer instrument. The standard calibration curve of fluorescence as a function of FITC-ODN concentration $(0.01,0.02$, 0.04 and $0.08 \mu \mathrm{M})$ was obtained using a fluorimeter $(\lambda=466 \mathrm{~nm}$ and $513 \mathrm{~nm}$ as excitation and emission wavelengths, respectively) (ESI, $\dagger$ Fig. S2).

\section{In vitro controlled release experiments from polysaccharide- based hydrogels}

Fluorescently labeled cationic nioplexes $(0.08-0.1 \mu \mathrm{M})$ entrapped into $\mathrm{KC}(4 \% ; \mathrm{w} / \mathrm{v})$ and $\mathrm{MC}: \mathrm{KC}$ hydrogels $(2 \% ; \mathrm{w} / \mathrm{v})$ (in total $4 \mathrm{wt} \%$ of polymers) (Hydrogel_3 and Hydrogel_4, respectively) were prepared and placed into a screw-capped glass vial $(4 \mathrm{~cm}$ length $x 1 \mathrm{~cm}$ diameter). $100 \mathrm{mM}$ PBS ( $\mathrm{pH} 7.4)(1 \mathrm{~mL}$ ) was added and used as a receptor phase. Hydrogels were incubated at $37 \stackrel{\circ}{C}$ as an isothermal condition to imitate cell culture conditions, which is the goal of this application. Aliquots $(1 \mathrm{~mL})$ were removed at selected time intervals and fluorescence was measured using a fluorimeter. Excitation and emission wavelengths were set to $466 \mathrm{~nm}$ and 513 $\mathrm{nm}$, respectively. The concentration of niosomal FITC-ODN was calculated via interpolation from a fluorescence standard curve against concentration. Total cumulative niosomal FITC-ODN release was obtained from eqn (2). All release experiments were carried out in duplicate (two independent experiments) in which the corresponding cumulative release percentage of niosomal FITC-ODN was plotted against time.

$$
\text { cumulative FITC-ODN }(\%)=\frac{\text { mass }(\text { total FITC-ODN,aliquots })}{\text { mass }(\text { initial } \text { FITC-ODN,loading })} \times 100 \quad \text { [eq. 2] }
$$

\section{Mathematical models}

The data obtained from the in vitro controlled release experiments were fitted according to three drug release mathematical models: Higuchi ${ }^{41}$ [eqn (3)], Korsmeyer-Peppas ${ }^{42}$ [eqn (4)] and Weibull ${ }^{43,44}$ [eqn (5)] equation models. $M_{t}$ and $M_{\infty}$ values correspond to the cumulative and the maximal amounts of drug released at time $t$, respectively. In the case of the Higuchi equation model, the drug released fraction is proportional to the square root of time $t$ in which $\mathrm{K}$ corresponds to the Higuchi constant. The Korsmeyer-Peppas equation model exponentially describes the relationship between the drug released fraction with the elapsed time $t$. $K$ is a rate constant and $\mathrm{n}$ is the release exponent that describes the release processes governed in the liberation of a drug: in particular, there is a Fickian 
mechanism (Case I) when $\mathrm{n}$ is around 0.5 and anomalous diffusion (non-Fickian) when $0.5<\mathrm{n}<1$ (Case II). In the case of the Weibull distribution, b parameter describes the diffusion mechanism: (a) Fickian when $b \leq 0.75$, and (b) others complex release processes combined with diffusion mechanisms when $0.75<b<1$.

$$
\begin{array}{lr}
\frac{M_{t}}{M_{\infty}}=K \times \sqrt{t} & \text { [eq. 3] } \\
\frac{M_{t}}{M_{\infty}}=K \times t^{n} & \text { [eq. 4] } \\
\frac{M_{t}}{M_{\infty}}=\alpha x\left(1-\exp \left(-(k t)^{b}\right)\right) & \text { [eq. 5] }
\end{array}
$$

\section{Stability of entrapped cationic nioplexes within KC and MC:KC polysaccharide-based hydrogels}

FITC-ODN $(1 \mu \mathrm{M})$ forming nioplexes based on niosome formulation made of cationic lipid_1 and polysorbate-80 were obtained in HEPES buffer $(300 \mu \mathrm{L}, \overline{\mathrm{pH}} 7.4,20 \mathrm{mM})$ as described above. Afterwards, complexes were carefully added and mixed with $\mathrm{KC}$ and $1: 1$ mixture of $\mathrm{MC}: \mathrm{KC}$ polymers. After polymer swelling, HEPES ( $1 \mathrm{~mL}$ of $20 \mathrm{mM}$ buffer solution) was added as a receptor phase. Hydrogels (_3 and _4) were incubated at $37 \stackrel{\circ}{\circ}$ for $24 \mathrm{~h}$ until hydrogels degradation. Fractions of the released nioplexes $(50 \mu \mathrm{L})$ were diluted in a $\mathrm{NaCl}$ solution ( $950 \mu \mathrm{L}$ from a $100 \mathrm{mM}$ solution). The hydrodynamic diameter of the complexes was measured using a Zetasizer Nano ZS (Malvern Instrument, Herrenberg, Germany) to determine size and dispersity index (D) at $25 \stackrel{\circ}{ }{ }^{\circ}$.

\section{Transmission electron microscopy (TEM)}

Cationic nioplexes based on a niosome formulation containing the cationic lipid_1, polysorbate-80 (Tween-80) and FITC-ODN ( $1 \mu \mathrm{M})$ were characterized by TEM microscopy. Nioplexes $(5 \mu \mathrm{L})$ were deposited onto glow discharged carbon coated grids for 1 min. The sample was stained with uranyl acetate $(2 \%)$ for $60 \mathrm{~s}$. Cationic nioplexes were observed by using a TECNAI G2 20 TWIN microscope (FEl, Eindhoven, The Netherlands) at an accelerating voltage (200 $\mathrm{keV}$ ) in a bright-field image mode. Pictures were obtained from an Olympus SIS Morada digital camera.

\section{Cryo-scanning electron microscopy (cryo-SEM)}

Hydrogels were firstly placed on a holder without using any additional preparation of the samples or fixative. Hydrogels were immersed in liquid nitrogen and finally freeze-dried. Materials were cut with an equipped cold knife and observed by using a Hitachi S3500N (Hitachi High-Technologies Corp., Tokyo, Japan) scanning electron microscope operated at $5 \mathrm{kV}$. 


\section{Cytotoxicity of polysaccharide-based hydrogels and cell encapsulation studies}

Toxicity studies were carried out using two strategies. In the first approach, cervical cancer cells (HeLa) were regularly passaged to maintain exponential growth. Cells were seeded $\left(510^{3}\right.$ cells per well) in the absence of antibiotics into a 96-well cell culture plate. Native KC $(4 \% ; w / v)$ (Hydrogel_1 ) and MC:KC (2\%; w/v) (in total 4 wt\% of polymers) (Hydrogel_2) were used as controls (mock). Cationic nioplexes were encapsulated within both hydrogels (Hydrogel_5 and 6) using two concentrations of an antisense oligonucleotide (Luc) (120 and $300 \mathrm{nM}$ ) and cationic niosomes (1.7 and $4.2 \mu \mathrm{M})$, respectively. The protocol for the preparation of hydrogels containing nioplexes was followed as described above. Hydrogels $(40 \mu \mathrm{L})$ (mock and hybrid materials) were placed in contact with HeLa cells and cultured at $37 \stackrel{\circ}{\circ}$ in DMEM $(200 \mathrm{~mL})$. After $24 \mathrm{~h}$ incubation, DMEM and degraded hydrogels were discharged. Cells were thoroughly washed with $1 \times$ PBS $(200 \mu \mathrm{L})$. Fresh DMEM ( $200 \mathrm{~mL})$ was added and

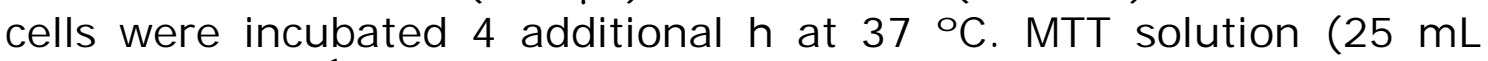
from $5 \mathrm{mg} \mathrm{mL}^{-1}$ solution in PBS) was added into wells and cells were incubated for another $4 \mathrm{~h}$. DMEM was removed and DMSO (100 $\mu \mathrm{L}$ ) was added to dissolve formazan crystals. After 15 min of shaking at RT, absorbance was measured at $560 \mathrm{~nm}$. Normalized cellular viabilities (\%) were expressed as a percentage relative to the untreated. All experiments were performed in sextuplicate in two independent experiments.

In the second approach, HeLa cells $\left(4 \times 10^{5}\right.$ cells $)$ were encapsulated within Hydrogel $2(80 \mu \mathrm{L})$. The obtained monolith containing living cells was cultured in DMEM ( $1 \mathrm{~mL}$ ) at $371 \mathrm{C}$ and $5 \%$ $\mathrm{CO}_{2}$ for $24 \mathrm{~h}$. DMEM was carefully removed and attached cells were washed with $1 \times$ PBS $(300 \mu \mathrm{L})$. Tripsin-EDTA $(150 \mu \mathrm{L})$ was then added and detached cells were suspended in DMEM (850 $\mu \mathrm{L})$ and pellet was centrifuged. Cells $\left(5 \times 10^{3}\right.$ cells) were seeded again in a 96-well cell culture plate. After $24 \mathrm{~h}$ incubation at 37 으, MTT solution (25 $\mu \mathrm{L}$ from $5 \mathrm{mg} \mathrm{mL}^{-1}$ solution in PBS) were added following the same experimental protocol as described above. Normalized cellular viabilities (\%) were expressed as a percentage relative to nonencapsulated control cells. Experiments were performed in triplicate in two independent experiments. Absorbance values were measured at $570 \mathrm{~nm}$ using a Promega Glomax Multidetection System microplate reader (Madison, WI, USA).

\section{Gene silencing studies}

HeLa cells were regularly passaged in order to maintain exponential growth. Cells were incubated in DMEM supplemented with $10 \%$ FBS without using antibiotics at $37 \stackrel{\circ}{\circ}$ and $5 \% \mathrm{CO}_{2}$. HeLa cells ( $10^{5}$ cells per well) were cultured in DMEM (supplemented with $10 \%$ FBS) and seeded into a 24-well cell culture plate in order to get 60- 


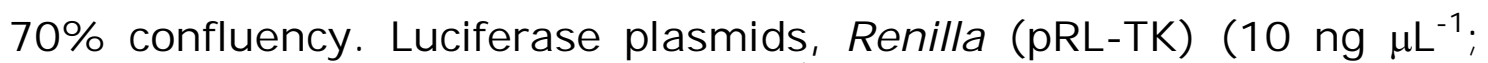
$10 \mu \mathrm{L}$ ) and Firefly (pGL4) (100 $\mathrm{ng} \mu \mathrm{L}^{-1} ; 10 \mu \mathrm{L}$ ) luciferase were used as a reporter and control respectively. Both plasmids were formulated and transfected in the presence of Lipofectamine2000 $(1.9 \mu \mathrm{L})$ in OptiMEM (total volume of $100 \mathrm{~mL}$ ) according to manufacturer's protocol. DMEM was removed after $5 \mathrm{~h}$ incubation at $37 \stackrel{\circ}{\circ}$ and cells were thoroughly washed with $1 \times$ PBS $(2 \times 300 \mu \mathrm{L})$. Fresh DMEM ( $10 \%$ FBS) was then added $(550 \mu \mathrm{L})$. Cationic nioplexes made of an antisense oligonucleotide (Luc) and a scrambled sequence (Scr) were previously obtained. Several concentrations of Luc and Scr were selected: (1) 60, 120 and $300 \mathrm{nM}$ for Luc oligonucleotide and (2) 300 $\mathrm{nM}$ for Scr oligonucleotide. Once cationic nioplexes were formed, they were entrapped into $50 \mu \mathrm{L}$ of $\mathrm{KC}(4 \% ; \mathrm{w} / \mathrm{v})$ (Hydrogel_5 and_7) and MC: KC $(2 \% ; w / v)$ (in total 4 wt\% of polymers) based hydrogels (Hydrogel_6 and 8). Hydrogels were immersed in DMEM and cultured for 24 and $48 \mathrm{~h}$ at $37 \stackrel{\circ}{\circ} \mathrm{C}$. After both incubation times, DMEM was discharged and cells were washed with 1PBS (300 mL). Finally, cell lysates were obtained (100 $\mu \mathrm{L} ; 1 \times$ lysis buffer) in order to measure Firefly and Renilla luciferase expression according to manufacturer's protocol. Normalized luciferase inhibition results were expressed as the average ratio between reporter and control (Renilla/Firefly). Cationic nioplexes containing Luc and $\mathrm{Scr}$ oligonucleotides without being encapsulated within hydrogels were also used as positive and negative controls, respectively. Transfection experiments were performed in sextuplicate in three independent experiments. The luciferase activities of all samples weremeasured in a Promega Glomax Multidetection System microplate reader (Madison, WI, USA) with a delay and integration time of $1 \mathrm{~s}$.

\section{Flow cytometry}

HeLa cells $\left(10^{5}\right.$ cells per well) were seeded on a 24 -well cell culture plate $(60-70 \%$ confluency). pGFP $(2 \mu \mathrm{g})$ was mixed with cationic niosomes $(30: 1 ; \mathrm{w} / \mathrm{w})$ in order to form fluorescently labeled cationic complexes. Nioplexes were incubated $30 \mathrm{~min}$ at $37 \stackrel{\circ}{\circ} \mathrm{C}$ and then encapsulated within KC $(4 \% ; \mathrm{w} / \mathrm{v})$ hydrogel $(50 \mathrm{~mL})$. The resulting hybrid material (Hydrogel_10) was immersed in DMEM (550 $\mathrm{mL})$ and incubated for $72 \mathrm{~h}$ at $37^{-} \circ \mathrm{o}$. pGFP $(2 \mu \mathrm{g})$ without forming complexes were also entrap into the same hydrogel as a negative control (Hydrogel_9). Formulated lipoplexes in the presence of lipofectamine was used as a positive control. Cells were washed with PBS $(3 \times 300 \mu \mathrm{L})$ and harvested with trypsin-EDTA $(150 \mu \mathrm{L})$ at $37 \stackrel{\circ}{\circ}$ for $5 \mathrm{~min}$. DMEM $(500 \mathrm{~mL}$ ) was added and cells were centrifuged ( 3 X (12.3 rpm, $8 \mathrm{~min}))$. Cell pellets were suspended in PBS $(200 \mu \mathrm{L})$ and fluorescently labeled cell populations were analyzed by flow cytometry. For each measurement, $10^{4}$ events were collected in a selected gate (R1), which corresponds to the HeLa cell population (control). A second region (R2) was defined to evaluate the number 
of positive GFP-cells. Flow cytometer analyses were carried out in a Guavas easyCyte 8HT instrument (Millipore; Billerica, MA, USA). Flowing Software 2.5.1 (University of Turku, Finland) was employed to measure the number of fluorescently labeled cells population containing GFP and compare it to untreated HeLa cells population.

\section{Statistical analysis}

All data were shown as mean \pm standard deviation (SD) and are the result of an average of 3-6 replicates in two random experiments. Statistical differences were determined using Student's t-test and were considered significant when $* \rho<0.05, * * \rho<0.01$ and $* * * \rho$ $<0.001$.

\section{Results and discussion}

\section{Formation and characterization of cationic nioplexes}

We have recently found that cationic lipids made of two hydrophobic alkyl chains, preferentially those containing fourteen atoms of carbons in length, a glycerol-based backbone and one cationic head (cationic lipid 1, Fig. 1) can give rise to niosomes when combined with non-ionic surfactant agents. ${ }^{24,26}$ Modification of both the cationic head and the glycerol backbone has allowed the fabrication of a series of niosomes ${ }^{45,46}$ which have been proved to be promising non-viral carriers for in vitro and in vivo release of antisense oligonucleotides (ASOs) ${ }^{26}$ and plasmid DNA. ${ }^{45}$

In order to evaluate the amount of niosomes required to form complexes with a fluorescently labeled oligonucleotide (FITC-ODN; sequence 1 ) (N/P ratio), we carried out a native electrophoretic mobility shift assay in a $20 \%$ polyacrylamide (PAGE) gel. As illustrated in Fig. 2, a fixed amount of FITC-ODN $(0.25 \mu \mathrm{M})$ was combined with increasing N/P ratios of cationic niosome formulation that ranged from 1 to 16 . The electrostatic interaction between positive charges of cationic niosomes and negatively charged oligonucleotide took place and therefore gave rise to the formation of the cationic nioplexes in a range of N/P ratios between 10 and $16 .^{26}$ This could be confirmed due to the disappearance of the oligonucleotide band in the PAGE gel after staining with SYBR-green II at these N/P ratios. In addition to FITC-ODN, cationic nioplexes based on antisense Luc and Scr oligonucleotides (sequence 2 and 3, respectively; Table 1) were also formed at N/P ratio of 14 .

It is well known that the applicability of niosomes as nonviral carriers may be limited in terms of stability in biological fluids and their rapid clearance in vivo. To overcome these obstacles, not only PEGylated and other second-generation vesicles have been 
successfully designed ${ }^{47}$ but also combining vesicle carriers within polymeric matrices have shown interesting therapeutic activities. ${ }^{14,48}$ With this in mind, the aforementioned nioplexes were entrapped into thermoresponsive polysaccharide-based hydrogels made of either $k$ carrageenan $^{49}(\mathrm{KC})(4 \% ; \mathrm{w} / \mathrm{v})$ or a $1: 1$ mixture of methylcellulose : k-carrageenan ${ }^{50}(\mathrm{MC}: \mathrm{KC})(2 \% \mathrm{w} / \mathrm{w})$ in the presence of HEPES buffer $(20 \mathrm{mM}, \mathrm{pH} 7.4)$. Thus, a series of hydrogels in combination with niosomal formulations of FITC-ODN (1), LuC (2) and $\mathrm{Scr}$ (3) oligonucleotides (cationic nioplexes) were obtained: (a) Hydrogel_3, Hydrogel_5 and Hydrogel_7, which were only made of KC polymer and (b) Hydrogel_4, Hydrogel_6 and Hydrogel_8, which were exclusively made of the mixture MC: KC (Table 1 ).

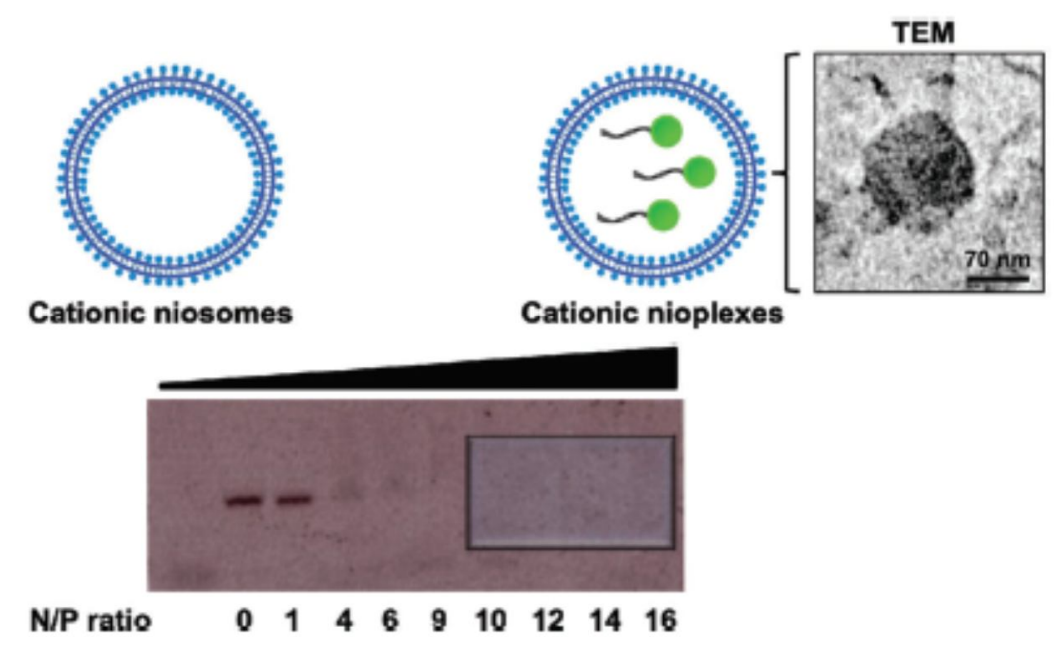

Fig. 2 Native PAGE gel (20\%) of cationic niosome-based formulations at different $\mathrm{N} / \mathrm{P}$ ratios ranging from 1 to 16 with a constant concentration of oligonucleotide $([$ FITC-ODN] $=0.25 \mu \mathrm{M})(\mathrm{N} / \mathrm{P}=0$ corresponds to a control sample). Cationic nioplexes were formed due to electrostatic interaction between cationic niosomes and anionic oligonucleotide at N/P ratios between 10 and 16 (area marked with a rectangle in the photograph of the PAGE gel), as demonstrated by the disappearance of the FITC-ODN band after staining with SYBR-green II. Top-right: TEM image of so-formed cationic nioplexes (magnification 40 000x). 
Table 1 Series of polysaccharide-based hydrogels prepared in this study and oligonucleotide sequences used for the preparation of cationic nioplexes at N/P ratio of 14 . Nioplexes based on pGFP were prepared at $30: 1(\mathrm{w} / \mathrm{w})$ ratio. Native Hydrogels_1 and _2 together with Hydrogel_10 were used as controls.

\begin{tabular}{|c|c|c|c|c|}
\hline Name $^{a}$ & Backbone $^{b}$ & 5'modification & $\mathrm{KC}^{\mathrm{c}}$ & $\mathrm{MC}: \mathrm{KC}^{\mathrm{c}}$ \\
\hline $\begin{array}{l}\text { FITC- } \\
\text { ODN }\end{array}$ & PO & Fluorescein & Hydrogel_3 & Hydrogel_4 \\
\hline Luc & PS & None & Hydrogel_5 & Hydrogel_6 \\
\hline Scr & PS & None & Hydrogel_7 & Hydrogel_8 \\
\hline pGFP $^{\mathrm{d}}$ & - & - & Hydrogel_9 & - \\
\hline $\mathrm{pGFP}^{\mathrm{e}}$ & - & - & Hydrogel_10 & - \\
\hline None & None & None & Hydrogel_1 ${ }^{\mathrm{f}}$ & Hydrogel_2 ${ }^{\mathrm{f}}$ \\
\hline
\end{tabular}

\section{Mechanical properties of polysaccharide-based hydrogels}

The viscoelastic properties of KC- and MC: KC-based hydrogels formed in the presence of cationic nioplexes containing FITC-ODN (Hydrogel_3 and Hydrogel_4, respectively) were confirmed by oscillatory rheological measurements. Additionally, native hydrogels made exclusively of KC (Hydrogel_1) and MC:KC (Hydrogel_2) were also measured as controls (Fig. 3 and ESI, $\dagger$ Table S1). The storage $\left(G^{\prime}\right)$ and loss modulus (G") were measured at constant temperature $(25 \stackrel{\circ}{ }$ ) as a function of the frequency (dynamic frequency sweep, DFS, Fig. 3A) and the shear strain (dynamic strain sweep, DSS, Fig. $3 B$ ) to define the linear viscoelastic regime (LVR) of the material. Reasonably constant dissipation factor tan $d\left(G^{\prime \prime} / G^{\prime}\right)$ during the measurements indicates a relative good tolerance of the materials towards external forces. The value of the storage modulus was nearly independent of the frequency in the range $0.01-10 \mathrm{~Hz}$ and it was always ca. one order of magnitude higher than the loss modulus for all hydrogels (Hydrogel_1-4). The encapsulation of nioplexes ([FITCODN] = $300 \mathrm{nM}$ ) in $\mathrm{KC}$ - and MC: KC-based hydrogels slightly weakened the networks as indicated by the increase of the $\tan \delta$ (Hydrogel_1 $=0.14$, Hydrogel_ $2=0.17$ vs. Hydrogel $3=0.21$, Hydrogel_ $\mathbf{4}=0.22)$, measured at constant frequency $(\overline{1} \mathrm{~Hz})$. This variation in the dissipated energy ratio might be attributed to possible frictions produced between cationic particles and polysaccharide chains. ${ }^{51-53}$ Thus, the presence of the niosome complexes embedded within the two hydrogels (Hydrogel_3 and Hydrogel_4) might produce certain rearrangements in the hybrid polymer network, which could affect the gelation processes when compared to native 
hydrogels (Hydrogel_1 and Hydrogel_2). Such differences could be more dramatic in the case of the most heterogeneous system (KC:MC, Hydrogel_3 and Hydrogel_4), where the overall heterogeneity could increase causing a detriment on the damping properties of these materials. However, additional experiments are still necessary to understand the underlying mechanisms that can explain these behaviors. DSS measurements also showed different yield shear stress for the native (Hydrogel_1 and 2 2) and hybrid materials (Hydrogel_3 and 4) (Fig. 3B), as indicated by their breaking strain $(\gamma)$ values. Interestingly, while the $\gamma$ values were not so different from each other in the case of the gels made of KC $(1.1 \%$ and $0.68 \%$ for Hydrogel_1 and_3, respectively), this difference was unexpectedly much more pronounced in the case of MC:KC-based hydrogels ( 41 and $3.9 \%$ for Hydrogel_2 and_4, respectively). This result suggest that the encapsulation of cationic nioplexes, in combination with a specific saline concentration, causes a particular large disruption of the crosslinked polymeric aggregates in case of MC: KC-based hydrogels, ${ }^{50,53-56}$ and thus reducing the strength of the networks. Finally, oscillatory time sweep measurements confirmed the stability of all hydrogel materials upon aging within the predetermined linear limits (Fig. 3C).

\section{In vitro release behavior and mathematical models}

The ability of Hydrogel_3 and Hydrogel_4 to release cationic nioplexes in a sustainable manner was investigated (Fig. 4). Both materials were placed in a screw-vial and immersed into a $100 \mathrm{mM}$ PBS solution buffer $(1 \mathrm{~mL})$ at $37 \stackrel{\circ}{ } \mathrm{C}$. Cumulative release of the cationic nioplexes were quantified by fluorescence at regular time intervals, using $\lambda=466 \mathrm{~nm}$ and $513 \mathrm{~nm}$ as excitation and emission wavelengths, respectively, and a proper calibration curve as a function of FITC-ODN concentration (ESI, $\dagger$ Fig. S2). FITC-ODN forming nioplexes were embedded into the two hydrogels with greater efficiencies (95.7 and $98.4 \%$ for Hydrogel_3 and _4, respectively). Both hydrogels displayed similar burst release patterns at early stages (14.6 vs. $13.2 \%$ in the first 20 min for Hydrogel_3 and _4, respectively). This behavior was shifted over time: while Hydrogel_3 practically liberated the niosomal formulation in its entirety after $11 \mathrm{~h}(97 \%)$, Hydrogel_4 was able to delay the niosomal release process (ca. 65\%) within the same time interval. Furthermore, it displayed better-long term responses and sustainedrelease properties than Hydrogel 3 (78\% of nioplexes liberated through the polymer network in $30^{-} \mathrm{h}$ vs. $97 \%$ in $11 \mathrm{~h}$ ) (Fig. $4 \mathrm{~A}$ and $B$ ). Such decline in the released FITC-ODN may be attributed to an increase of the heterogeneity of the network in the case of hydrogels based on the mixture MC: $K C$, being less prone to erosion processes in comparison to the matrices made only of KC (Hydrogel_3). ${ }^{57}$ 
The cumulative release data were further fitted using Higuchi ${ }^{41}$ [ eqn (3)], Korsmeyer-Peppas ${ }^{42}$ [eqn (4)] and Weibull ${ }^{43,44}$ [eqn (5)] equation models. These results confirmed that nioplexes obeyed diffusion mechanisms when released through $\mathrm{KC}$ and $\mathrm{MC}: \mathrm{KC}$ hydrogels. Release curves from polysaccharide-based hydrogels offered a better correlation ${ }^{58}$ for the Korsmeyer-Peppas equation than the rest of the kinetic models studied (Fig. 4). According to this equation, the diffusion coefficient $(n)$ calculated for Hydrogel_ 3 and Hydrogel_4 were 0.55 and 0.41 , respectively, which is characteristic for Fickian diffusions. All parameters and release coefficients are displayed on ESI, $\dagger$ Tables S2-S4.

The structural integrity of cationic nioplexes entrapped in and released from KC and MC:KC hydrogels (Hydrogel_3 and 4, respectively) was confirmed by dynamic light scattering (DLS). ${ }^{-59}$ Measurements were carried out after complete network degradation (ESI, † Fig. S4). Plain nioplexes based on fluorescently labeled FITCODN showed a diameter of $115.4 \pm 5 \mathrm{~nm}$ in solution prior encapsulation in both hydrogels. KC and MC: KC monolithic hydrogels were incubated at $37 \stackrel{\circ}{\circ}$ to trigger erosion and liberate the corresponding nioplexes (formed with $1 \mu \mathrm{M}$ of FITC-ODN) into the receptor phase. The results showed that the released nioplexes from KC hydrogels followed a bimodal distribution with similar diameter averages and acceptable dispersity index values as observed for nonencapsulated nioplexes ( $124 \mathrm{~nm}, \mathrm{D}=0.410$ vs. $115 \mathrm{~nm}, \mathrm{D}=0.301$ for Hydrogel_3 and nioplex control, respectively) (ESI,† Fig. S4A). These findings were also corroborated by cryo-SEM observations, which showed the presence of intact nioplexes within the KC polymer matrix (ESI, $\dagger$ Fig. S5). These data confirmed the stability of the released nioplexes from $\mathrm{KC}$ hydrogels without apparent changes in their morphology after hydrogel degradation.

However, a different behavior was observed for MC: KC hydrogels (Hydrogel_4). In this case, cationic nioplexes lost their vesicle structure since they exhibited a greater average diameter and elevated dispersity degree after supernatant analyses $(538 \mathrm{~nm}$ and $Ð$ $=0.742)(E S I, \dagger$ Fig. S4B). This different behavior of both hydrogels is not totally unexpected because the stability of embedded complexes depends on several factors such as nature of the polymer, stimuli-responsiveness properties of the network (e.g. temperature), presence of functional groups and zeta potential. ${ }^{60}$ According to cryoSEM measurements, hydrogels based on 1 : 1 mixture of MC: KC showed tightly entanglements which might primarily affect the nioplexes stability during the release from the gel network (ESI, $\dagger$ Fig. S6). It is also worthmentioning that these changes in the liposomes morphology have been observed in other kinds of materials like thermoresponsive PNIPAm hydrogels, which have affected the liposomes integrity at temperatures above their sol-gel transition temperature. ${ }^{61}$ 


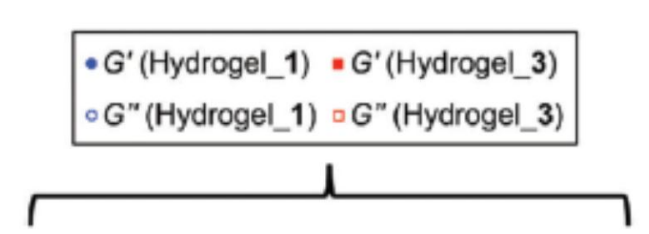

A
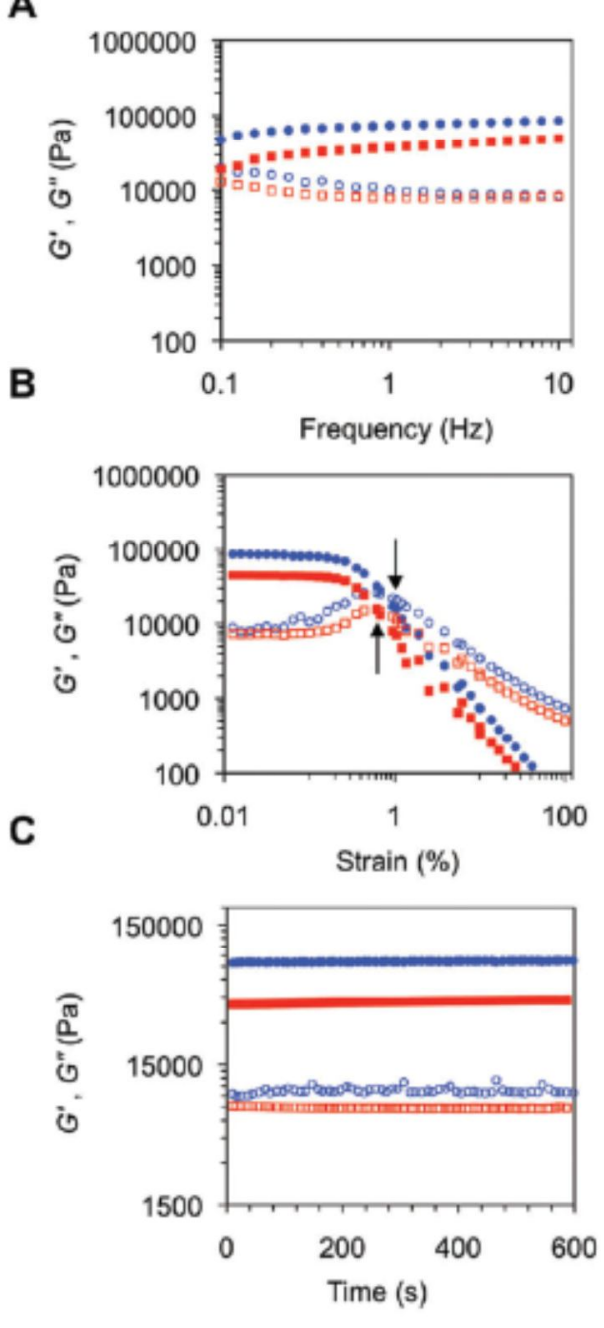

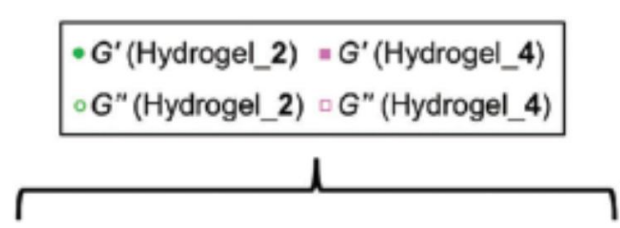

D
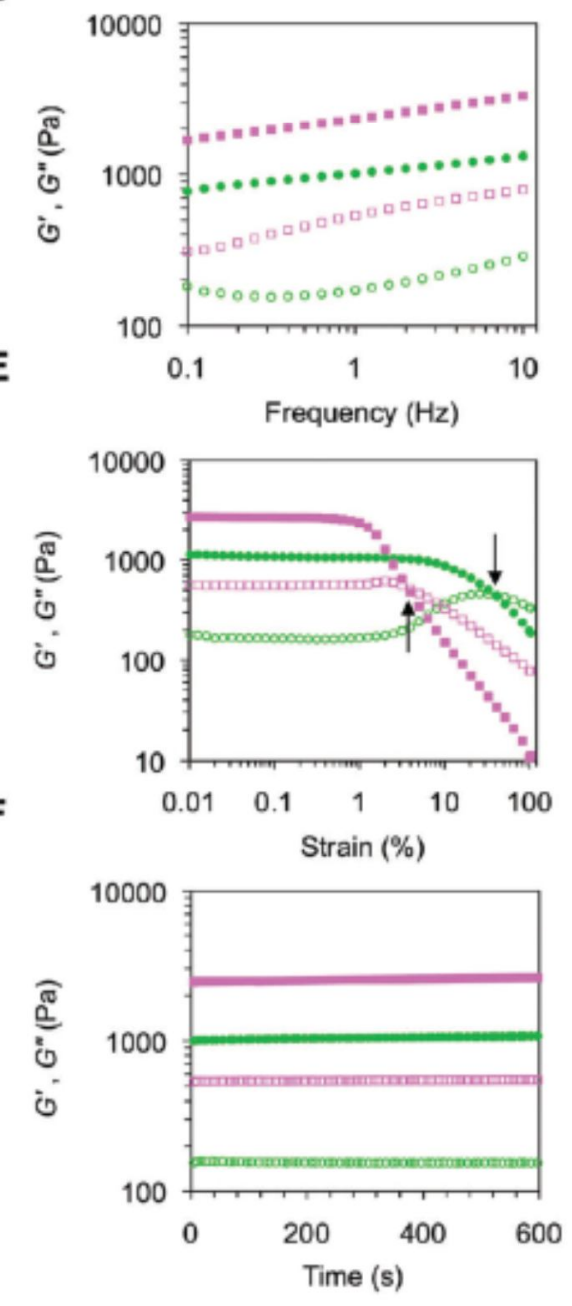

Fig. 3 Rheological properties of $K C$ and 1 : 1 mixture of $M C$ : $K C$ polysaccharide-based hydrogels containing cationic nioplexes (Hydrogel_3 and Hydrogel_4, respectively). (A and D) Comparative DFS measurements: (A) Hydrogel_1 and Hydrogel_3; (D) Hydrogel_2 and Hydrogel_4. (B and E) Comparative DSS measurements: (B) Hydrogel_1 and Hydrogel_3; (E) Hydrogel_2 and Hydrogel_4. ( $C$ and $F$ ) Comparative DTS measurements: (C) Hydrogel_1 and Hydrogel_3; (F) Hydrogel_2 and Hydrogel_4. The cross-point between $G^{\prime}$ and $G^{\prime \prime}$ is shown ( $g$ at break). Hydrogels were prepared in HEPES buffer $(20 \mathrm{mM}, \mathrm{pH} 7.4)$ and measured at RT. Native Hydrogel_1 and Hydrogel_2 were prepared and evaluated as controls for comparison purposes. FITC-ODN was the modified oligonucleotide used for the preparation of cationic nioplexes at N/P ratio of 14 and $300 \mathrm{nM}$. 

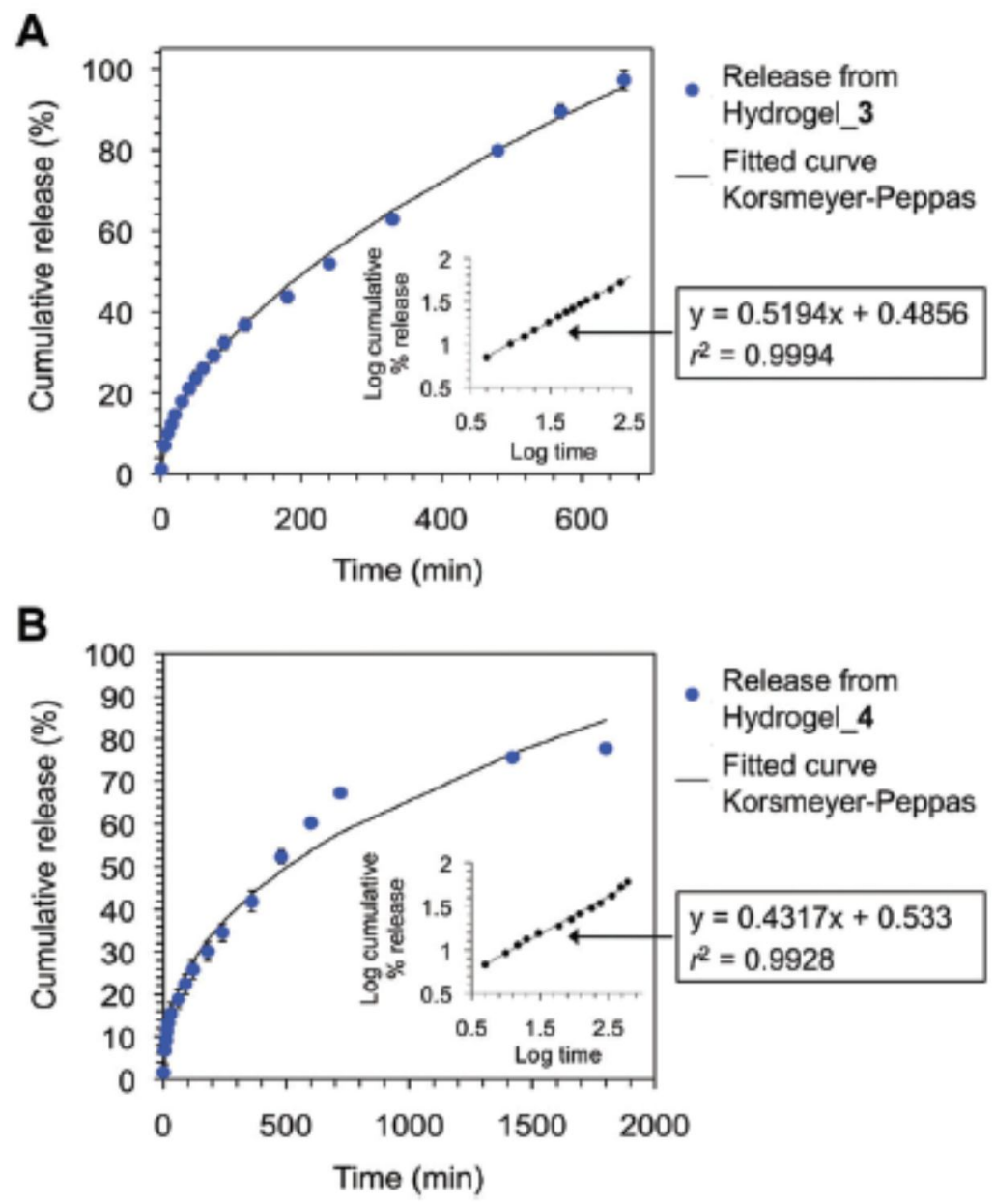

Fig. 4 In vitro cumulative release of FITC-ODN forming nioplexes embedded within (A) KC hydrogels (Hydrogel_3) and (B) MC:KC hydrogels (Hydrogel_4) at $37 \stackrel{\circ}{\circ} \mathrm{C}$. Release curves were fitted according to Korsmeyer- Peppas equation [eqn (4)]. Fitting parameters can be found on ESI. $\dagger$ Insets in both release curves are the log time-log cumulative release when $60 \%$ of material was released. Data were means \pm SD of two independent experiments. A fixed concentration of FITC-ODN was used for in vitro controlled release experiments $(0.5 \mu \mathrm{M})$.

\section{Cytotoxicity studies}

The toxicity of $\mathrm{KC}$ and $\mathrm{MC}: \mathrm{KC}$ hydrogels containing cationic nioplexes was investigated. A 17-mer phosphorothioate oligonucleotide was selected (Luc sequence; Table 1) in order to obtain the anticipated complexes with the niosome formulation at the same N/P ratio of 14 . The resultant nioplexes were then entrapped into KC (Hydrogel_5) and MC:KC (Hydrogel_6), respectively.

The metabolic activity generated by cervical cancer cells when incubated in the presence of Hydrogel_5 and _6 was measured by 
using the MTT colorimetric assay. ${ }^{62}$ Two concentrations of cationic nioplexes embedded within both hydrogels were tested (120 and 300 $\mathrm{nM}$ referred to Luc concentration which corresponded to 1.7 and 4.2 $\mu \mathrm{M}$ of cationic lipid concentration, respectively). The resultant hybrid materials were incubated with HeLa cells 24 h at $37 \stackrel{\circ}{ }$. Native hydrogels ( $\mathbf{1}$ and $\mathbf{2}$ ) (mock) were used as controls. As illustrated in Fig. 5A, both non-encapsulated (Hydrogel_1 and_2) and hydrogels containing nioplexes (Hydrogel_5 and_-6) gave cellular viabilities greater than $90 \%$ in the case of KC hydrogels and $80 \%$ for the hydrogels made of the mixture MC: KC at the same concentrations. This result confirmed that hybrid hydrogels modified with cationic particles did not affect to HeLa cellular viabilities and therefore could be used in later transfection experiments.

At this point, 3D-encapsulation of living cells and following cell release studies were carried out in order to gain further insight into the effect of MC:KC hydrogels (Hydrogel_2) in the viability of HeLa cells (Fig. 5B). Monolith containing carcinoma cells was immersed in DMEM and incubated for $24 \mathrm{~h}$ at $37^{\circ} \mathrm{C}$. Erosion processes took place because of the temperature as stimulus and thus caused the expected release of cells through the hydrogel network. After spreading and sticking on the cell culture plate, HeLa cells were able to proliferate (cellular viabilities greater than $85 \%$ according to MTT studies) (Fig. 5B) and showed normal cell morphology after incubation when compared to non-encapsulated cells (Fig. 5C and D). 
A
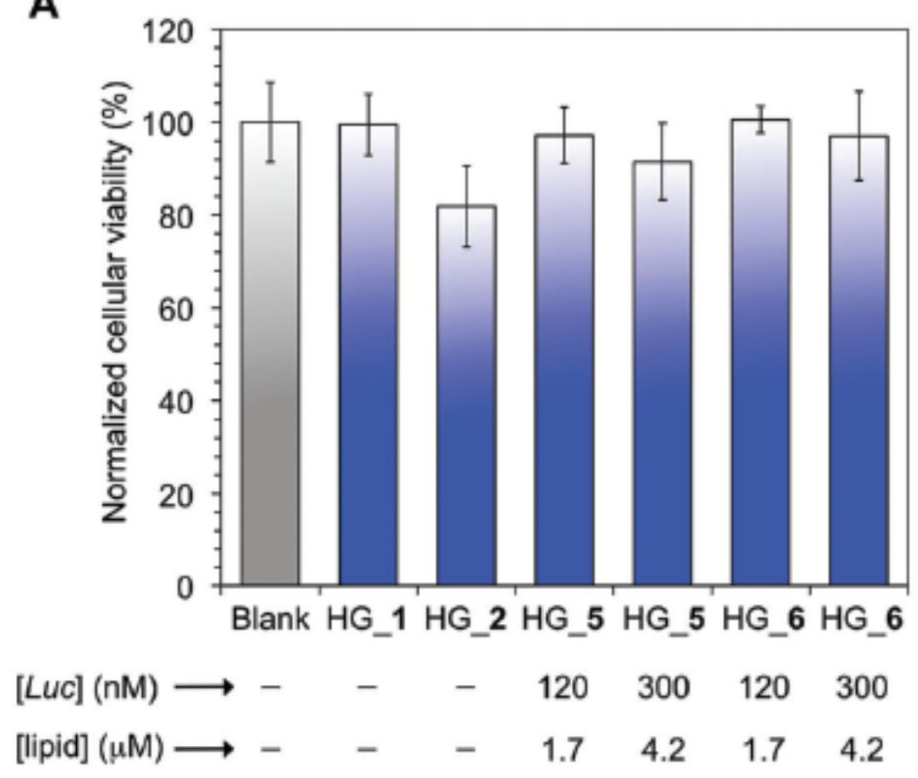

B

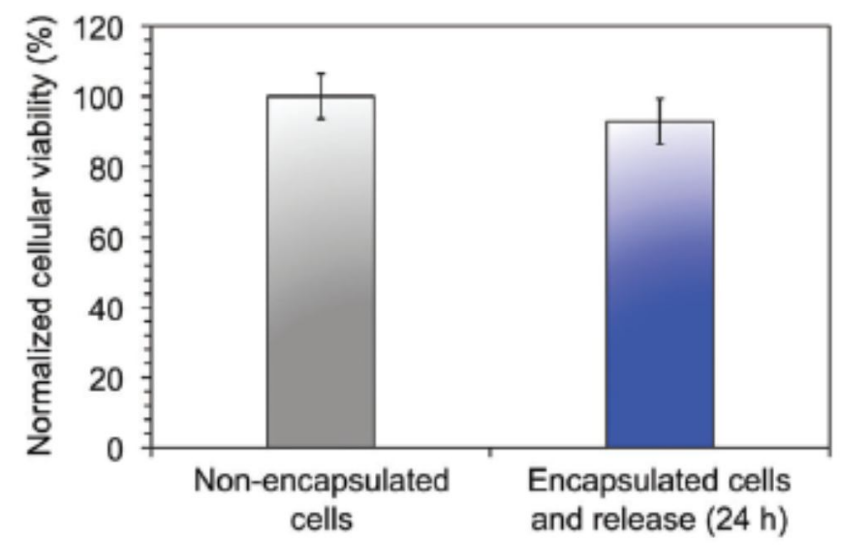

C

D
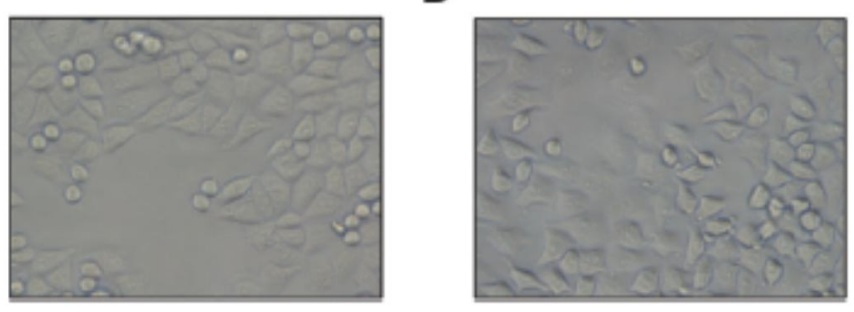

Fig. 5 Cellular viabilities of HeLa cells according to the MTT colorimetric assay. (A) MTT assay which shows the cytotoxicity of cationic nioplexes-inhydrogels was evaluated using 120 and $300 \mathrm{nM}$ of Luc oligonucleotide. 1.7 and $4.2 \mu \mathrm{M}$ of cationic niosomes were also tested. Hydrogel_1 and_2 were tested as controls (in the absence of cationic nioplexes). Abbreviation: HG = hydrogel. (B) MTT assay of encapsulated cells after releasing through the Hydrogel_2. Nonencapsulated cells were tested as a positive control. ${ }^{-}$(C) Cell morphology of non-encapsulated cells (control). (D) Cell morphology of encapsulated HeLa cells after $24 \mathrm{~h}$ incubation. 


\section{Gene transfection and cellular uptake studies}

As the presence of $\mathrm{KC}$ and MC: KC hydrogels did not produce any undesirable effect in cell viability, the efficiency of entrapped cationic nioplexes were evaluated in antisense technology. ${ }^{63}$ These complexes, obtained from the niosome formulation based on cationic lipid_1, were designed to knockdown Renilla luciferase mRNA by using a phosphorothioate (Luc) oligonucleotide of sequence d(5'-CGT TTC CTT TGT TCT GGA-3'). ${ }^{64}$ Additionally, a scrambled (Scr) oligonucleotide of sequence d(5'-CTG TCT GAC GTT CTT TGT-3') was also selected as a negative control. The resultant nioplexes were obtained at 60, 120 and $300 \mathrm{nM}$ of Luc and only at $300 \mathrm{nM}$ for Scr oligonucleotide. Finally, the preformed complexes were entrapped into KC (Hydrogel_5 and_7) and MC:KC hydrogels (Hydrogel_6 and 8 containing the niosomal formulations based on Luc and $\mathrm{Scr}$, respectively).

Hydrogels containing nioplexes were immersed in DMEM (supplemented with $10 \%$ FBS) and cultured in contact with cells at 37 o $\mathrm{C}$ for either $24 \mathrm{~h}$ or $48 \mathrm{~h}$ depending on the hydrogel material. The relationship between Renilla (reporter) and Firefly (control) showed the silencing efficiency of the released nioplexes involved in this study (Fig. 6). According to DLS measurements described above, KC and MC: KC hydrogels showed different behavior when cultured with time (up to $24 \mathrm{~h}$ ). While nioplexes practically remained unchanged within KC hydrogels with time, hydrogels made of a mixture of MC: KC remarkably affected the nioplex stability after $24 \mathrm{~h}$. This opposite behavior among these polymeric networks might be reflected in the liberation of cationic nioplexes through both hydrogels and therefore obtaining unalike silencing efficiencies at mRNA level.

As observed in Fig. 6, nioplexes that released from $\mathrm{KC}$ and MC: KC hydrogels were able to silence luciferase in all tested concentrations but displayed different profiles after $24 \mathrm{~h}$ (Hydrogel_5 and_6) and $48 \mathrm{~h}$ (Hydrogel_5). The liberation of cationic nioplexes from Hydrogel_ 6 produced the inhibition of luciferase production in a dose-response manner and showed better antisense activities than KC hydrogels $(26,29$ and $38 \%$ vs. 5, 17 and 23\% for Hydrogel_6 and 5 at 60,120 and $300 \mathrm{nM}$, respectively). However, the increasing size experienced by these vesicular carriers ${ }^{65}$ within MC: KC hydrogels could explain such antisense activities observed at the first $24 \mathrm{~h}$ incubation. Interestingly, significant silencing activities were found at the three concentrations tested when the incubation time was prolonged up to $48 \mathrm{~h}$ in the case of Hydrogel_5. Thus, released nioplexes afforded luciferase inhibition efficiencies of $40 \%$ at $60 \mathrm{nM}$ $(* * * \rho<0.001) ; 39 \%$ at $120 \mathrm{nM}(* * * \rho<0.001)$ and $51 \%$ at $300 \mathrm{nM}$ $(* * \rho<0.01)$, respectively. These silencing activities achieved at $48 \mathrm{~h}$ were slightly better than those obtained at the first $24 \mathrm{~h}$ incubation. These interesting results may bring to light that antisense nioplexes might become released in a controlled manner obtaining the anticipated therapeutic activity at longer times of incubation. Same 
cationic nioplexes based on Luc oligonucleotide without being entrapped within KC hydrogels were used as control. In this case, silencing activities displayed a dose-response profile and obtained similar efficiencies to those previously described $(53,82$ and $95 \%$ for 60,120 and $300 \mathrm{nM}$, respectively). ${ }^{26}$ Furthermore, KC and MC: KC hydrogels (Hydrogel_ 1 and Hydrogel_2; mock), hydrogels containing nioplexes based on scrambled sequences (Hydrogel_ 7 and Hydrogel_8) as well as nioplexes based on a scrambled oligonucleotide in solution at $300 \mathrm{nM}$ did not affect the transfection process and luciferase production, which confirmed the specificity of the process.

Besides the antisense activity promoted by entrapped nioplexes, the ability of nioplexes to impart cellular uptake was studied by evaluating the amount of GFP produced in HeLa cells. Thus, pGFP forming nioplexes were obtained in HEPES buffer $(20 \mathrm{mM}$, $\mathrm{pH}$ 7.4) at a ratio $30: 1$ (w/w; cationic lipid : pGFP) using the same cationic niosome solution based on the cationic lipid_1. Nioplexes containing pGFP were then entrapped in KC hydrogels ( $\bar{H}_{\text {ydrogel_ 10) }}$ according to the same procedure described above and cultured under standard conditions ( $\left.72 \mathrm{~h}, 37^{\circ} \mathrm{\circ}\right)$. As a negative control, pGFP was directly entrapped in KC hydrogel (Hydrogel_9) and cultured under the same conditions. After nioplexes and pGFP were released from Hydrogel_9 and 10, respectively, HeLa cells were thoughtfully washed with phosphate saline buffer and fluorescence intensity was measured by flow cytometry. The cellular uptake process was evaluated by evaluating the fluorescence changes between nontreated cells (control, Fig. B1, B2 and C1, C2) and fluorescently labelled cell populations (Fig. B3 and C3). The relationship between fluorescently labeled cell populations and non-labeled cells indicated that the use of entrapped nioplexes within Hydrogel_10 generated a low GFP production in cells $(2.64 \pm 0.35 \%$ of GFP-labeled cell population). However, this value was greater than that obtained from the experiments carried out in the absence of non-viral gene carriers ( $0.08 \%$ of GFP-positive cells) (Fig. 6B and C, respectively). Finally, the presence of positive cell populations showed a slight histogram shift when compared to non-treated cell populations (Fig. 6C). Additionally, pGFP was formulated with Lipofectamine2000 to form the resultant lipoplexes in solution, as positive control, which were directly transfected to cells producing up to $90 \%$ of transfected GFPpositive cells (ESI, $\dagger$ Fig. S7). 
A
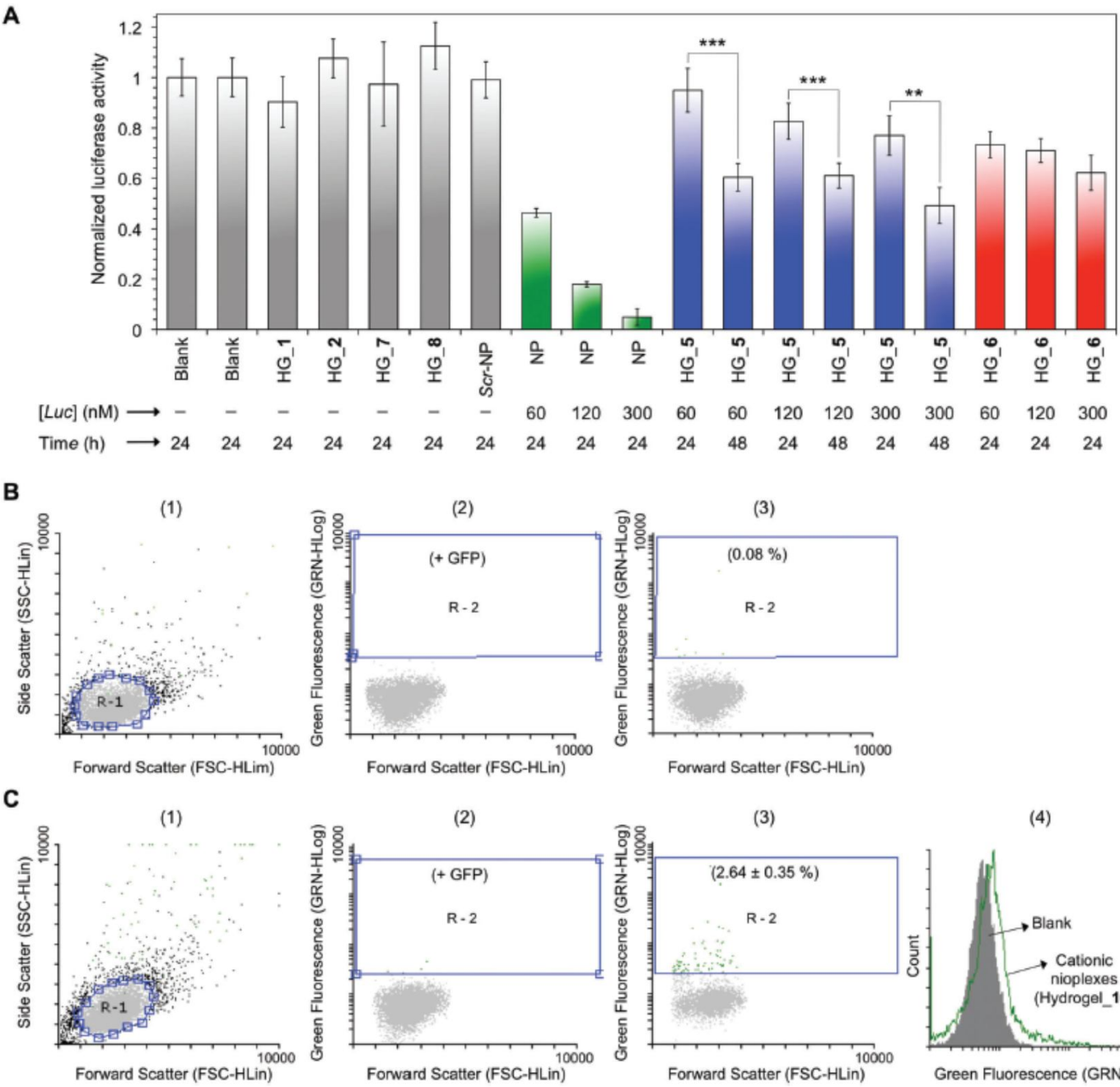

(3)

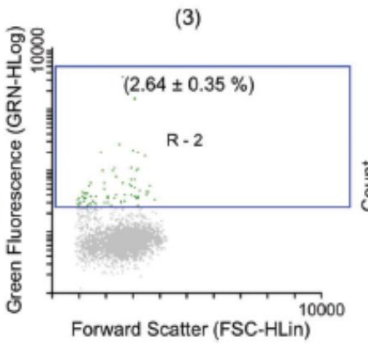

(4)

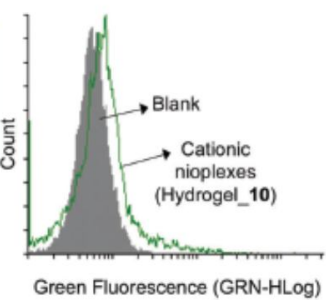

Fig. 6 (A) Dose-response experiments targeting Renilla luciferase mRNA in the absence of lipofectamine. Cationic nioplexes based on Luc oligonucleotide $(60,120$ and $300 \mathrm{nM})$ were entrapped in KC- and MC:KC-based hydrogels (Hydrogel_5 and Hydrogel_6, respectively). A scrambled sequence entrapped in KC hydrogel (Hydrogel_7) and MC: KC hydrogel (Hydrogel_8), native hydrogels (mock) as well as a nioplex based on a Scr oligonucleotide were used as negative controls. Inhibition activities of Hydrogel_5 containing cationic nioplexes at $24 \mathrm{~h}$ and $48 \mathrm{~h}$ of incubation were statistically significant based on the paired two-tailed t-test. Data were means $\pm S D$ of three to six replicates of three independent experiments. Abbreviation: HG $=$ hydrogel. $\mathrm{NP}=$ nioplex. $(\mathrm{B}$ and $\mathrm{C})$ Flow cytometry analyses in HeLa cells from Hydrogel_9 and Hydrogel_10 to entrap pGFP without forming complexes and pGFP forming nioplexes in KC hydrogels, respectively. ( $B 1$ and $\mathrm{C} 1$ ) Normal cell population. ( $B 2$ and $C 2$ ) Control and selection of a positive GFP region (R2). (B3 and C3) Flow cytometry showing positive-GFP cell populations from Hydrogel_ 9 and Hydrogel_10 after $72 \mathrm{~h}$ incubation. (C4) Histogram showing a shift between cells populations containing GFP and non-labeled cells after $72 \mathrm{~h}$ incubation when Hydrogel_10 was used. 


\section{Conclusions}

In conclusion, cationic nioplexes formed by mixing the cationic lipid_1, polysorbate-80 and a nucleic acid (i.e. FITC-ODN, antisense oligonucleotide or pGFP), were successfully encapsulated within polysaccharide-based hydrogels (e.g. k-carrageenan (KC) or 1 : 1 mixture of methylcellulose : $k$-carrageenan (MC: $K C)$. The entrapment of the nioplexes caused no critical changes on the gel properties, which could compromise the stability of the bulk material.Moreover, both native and nioplex-containing biohydrogels showed no cytotoxicity in cells, maintaining both their mitochondrial activity and proliferation capacity of encapsulated living cells. So formed nioplexcontaining biohydrogels were found to act as dual systems for the in vitro controlled release of niosomal formulations. Specifically, nioplexes entrapped within MC:KC-based hydrogel (Hydrogel_4) were liberated in a more sustainable manner than in the case of the KCbased hydrogel (Hydrogel_3), probably due to the higher heterogeneity of the polymer network in the former case. In this regard, while practically the entire formulation was released in the case of KC hydrogels, ca. $80 \%$ of the niosomal formulation was released during the same incubation time when MC:KC hydrogels were used. The resultant release curves fitted well to KorsmeyerPeppas model and followed a Fickian diffusion-controlled mechanism. Moreover, the feasibility of the KC-based hydrogel containing cationic niosomes in antisense therapy was also demonstrated. Thus, nioplexes bearing phosphorothioate oligonucleotide (Luc) were able to maintain their size when released through the KC-based hydrogel (Hydrogel_5), which resulted in inhibiting luciferase production in a dose-response manner within $48 \mathrm{~h}$. Finally, cellular uptake experiments were also carried out by entrapping pGFP-containing nioplexes within KC hydrogels (Hydrogel_10). Flow cytometry analysis demonstrated the presence of fluorescently labeled cell populations after releasing the cationic nioplexes from the hydrogel matrix. In principle, other hydrogel systems with similar physicochemical properties than those reported in this work could also lead to similar performance. In contrast to biohydrogels, toxicity issues at certain concentrations as well as poor mechanical properties may hinder the use of other synthetic gels, especially physical (or supramolecular) gels. Overall, based on these encouraging results, in vivo experiments based on Hydrogel_5 and Hydrogel_10 formulations are planned for future work.

\section{Conflicts of interest}

There are no conflicts to declare. 


\section{Acknowledgements}

This work was supported by the Spanish Ministry of Education (Grant CTQ2014-52588-R, RTC-2014-2038-1), the University of Regensburg, the Deutsche Forschungsgemeinschaft (DFG) (DI 1748/3-1 and 1748/3-2), the Generalitat de Catalunya (2014/ SGR/624) and the Instituto de Salud Carlos III (CB06_01_0019). S. G. thanks the Spanish Ministry of Education, Culture and Sports for a "Jose" Castillejo" grant within the researcher mobility program. D. D. D. thanks the DFG for the Heisenberg Professorship Award. We thank Prof. Dr Achim Göpferich for granting us access to the rheometer, Dr Gemma Fabriàs for assistance and access to the cytometer and the Nanostructured Liquid Characterization Unit (U12, CIBER-BBN Research Infrastructures, NANBIOSIS), especially, Dr Maria Homs and $\mathrm{Dr}$ José Rodrigo Magaña for their help with DLS measurements. Authors also thank the Electron Microscopy Service from the Institute of Marine Sciences (CSIC), especially Jose Manuel Fortuño for sample preparation and cryo-SEM observations.

\section{Notes and references}

1 S. W. Kim, Y. H. Bae and T. Okano, Pharm. Res., 1992, 9, 283290.

2 T. R. Hoare and D. S. Kohane, Polymer, 2008, 49, 1993-2007.

3 W. E. Hennink and C. F. van Nostrum, Adv. Drug Delivery Rev., 2012, 64, 223-236.

4 O. Wichterle and D. Lím, Nature, 1960, 185, 117-118.

5 N. A. Peppas, J. Z. Hilt, A. Khademhosseini and R. Langer, Adv. Mater., 2006, 18, 1345-1360.

6 R. Barbucci, M. Consumi, S. Lamponi and G. Leone, Macromol. Symp., 2003, 204, 37-58.

7 K. H. Bae, L.-S. Wang and M. Kurisawa, J. Mater. Chem. B, 2013, 1, 5371-5388.

8 Y. Li, J. Rodrigues and H. Tomás, Chem. Soc. Rev., 2012, 41, 2193-2221.

9 G. D. Nicodemus and S. J. Bryant, Tissue Eng., Part B, 2008, 14, 149- 165.

10 E. Rodríguez-Velázquez, M. Alatorre-Meda and J. F. Mano, Curr. Pharm. Des., 2015, 21, 4837-4850.

11 S. P. Bird and A. L. Baker, Analyst, 2011, 136, 3410-3418.

12 A. Sizovs, P.M. McLendon, S. Srinivasachari and T.M. Reineke, Top. Curr. Chem., 2010, 296, 131- 190.

13 K. Ganguly, K. Chaturvedi, U. A. More, M. N. Nadagouda and T. M. Aminabhavi, J. Controlled Release, 2014, 193, 162-173.

14 S. Grijalvo, J. Mayr, R. Eritja and D. Díaz Díaz, Biomater. Sci., 2016, 4, 555-574.

15 M. D. Krebs, O. Jeon and E. Alsberg, J. Am. Chem. Soc., 2009, 131, 9204-9206.

16 J. B. Opalinska and A. M. Gewirtz, Nat. Rev. Drug Discovery, 2002, 1, 503-514. 
17 J. C. Burnett and J. J. Rossi, Chem. Biol., 2012, 19, 60-71.

18 K. Sridharan and N. J. Gogtay, Br. J. Clin. Pharmacol., 2016, 82, 659-672.

19 M. Foldvari, D. W. Chen, N. Nafissi, D. Calderon, L. Narsineni and A. Rafiee, J. Controlled Release, 2016, 240, 165- 190.

20 X. Cheng and R. J. Lee, Adv. Drug Delivery Rev., 2016, 99, 129137.

21 M. Kapoor, D. J. Burgess and S. D. Patil, Int. J. Pharm., 2012, 427, 35- 57.

22 K. T. Love, K. P. Mahon, C. G. Levins, K. A. Whitehead, W. Querbes, J. R. Dorkin, J. Qin, W. Cantley, L. L. Qin, T. Racie, M. F Kamenetsky, K. N. Yip, R. Álvarez, D. W. Y. Sah, A. de Fougerolles, K. Fitzgerald, V. Koteliansky, A. Akinc, R. Langer and D. G. Anderson, Proc. Natl. Acad. Sci. U. S. A., 2010, 107, 1864-1869.

23 I. F. Uchegbu and S. P. Vyas, Int. J. Pharm., 1998, 172, 33- 70.

24 G. P. Ochoa, J. Z. Sesma, M. A. Díez, A. Díaz-Tahoces, M. AvilésTrigueros, S. Grijalvo, R. Eritja, E. Fernández and J. L. Pedraz, Pharm. Res., 2014, 31, 1665-1675.

25 Y. Huang, J. Chen, X. Chen, J. Gao and W. Liang, J. Mater. Sci.: Mater. Med., 2008, 19, 607-614.

26 S. Grijalvo, A. Alagia, G. Puras, J. Zárate, J. L. Pedraz and R. Eritja, Colloids Surf., B, 2014, 119, 30-37.

27 Y. Huang, Y. Rao, J. Chen, V. C. Yang and W. Liang, J. Biomed. Mater. Res., Part A, 2011, 96, 513-519.

28 D. Gu, A. J. O'Connor, G. G. H. Qiao and K. Ladewig, Expert Opin. Drug Delivery, 2017, 14, 879-895.

$29 \mathrm{~J}$. Li and D. J. Mooney, Nat. Rev. Mater., 2016, 1, 16071.

30 E. A. Appel, M. W. Tibbitt, M. J. Webber, B. A. Mattix, O. Veiseh and R. Langer, Nat. Commun., 2015, 6, 1-8.

31 F. Lim and A. M. Sun, Science, 1980, 210, 908-910.

32 D. Seliktar, Science, 2012, 336, 1124-1128.

33 L. Gasperini, J. F. Mano and R. L. Reis, J. R. Soc., Interface, 2014, $11,20140817$.

34 P. M. Rocha, V. E. Santo, M. E. Gomes, R. L. Reis and J. F. Mano, J. Bioact. Compat. Polym., 2011, 26, 493-507.

35 K. Raemdonck, T. F. Martens, K. Braeckmans, J. Demeester and S. C. De Smedt, Adv. Drug Delivery Rev., 2013, 65, 1123-1147.

36 Y. Lei, S. Huang, P. Sharif-Kashani, Y. Chen, P. Kavehpour and T. Segura, Biomaterials, 2010, 31, 9106-9116.

37 Y. Lei, M. Rahim, Q. Ng and T. Segura, J. Controlled Release, 2011, 153, 255-261.

38 S. Grijalvo, G. Puras, J. Zárate, R. Pons, J. L. Pedraz, R. Eritja and D. Díaz Díaz, RSC Adv., 2016, 6, 39688-39699.

$39 \mathrm{~J}$. Schulze, S. Hendrikx, M. Schulz-Siegmund and A. Aigner, Acta Biomater., 2016, 45, 210-222.

40 S. Pérez-Rentero, S. Grijalvo, G. Pen uelas, C. Fa` brega and R. Eritja, Molecules, 2014, 19, 10495-10523.

41 T. Higuchi, J. Pharm. Sci., 1963, 52, 1145- 1149. 
42 P. L. Ritger and N. A. Peppas, J. Controlled Release, 1987, 5, 3742.

43 W. Weibull, J. Appl. Mech., 1951, 18, 293-297.

44 F. Langenbucher, J. Pharm. Pharmacol., 1972, 24, 979-981.

45 E. Ojeda, G. Puras, M. Agirre, J. Zárate, S. Grijalvo, R. Eritja, G. Martínez-Navarete, C. Soto-Sánchez, A. Dáaz-Tahoces, M. AvilesTrigueros, E. Fernández and J. L. Pedraz, Biomaterials, 2016, 77, 267-279.

46 E. Ojeda, G. Puras, M. Agirre, J. Zárate, S. Grijalvo, R. Pons, R. Eritja, G. Martínez-Navarrete, C. Soto-Sánchez, E. Fernández and J. L. Pedraz, Org. Biomol. Chem., 2015, 13, 1068-1081.

47 B. S. Pattni, V. V. Chupin and V. P. Torchilin, Chem. Rev., 2015, 115, 10938-10966.

48 S. Thirumaleshwar, P. K. Kulkarni and D. V. Gowda, Curr. Drug Ther., 2012, 7, 212-218.

49 E. G. Popa, P. P. Carvalho, A. F. Dias, T. C. Santos, V. E. Santo, A. P. Marques, C. A. Viegas, I. R. Dias, M. E. Gomes and R. L. Reis, J. Biomed. Mater. Res., Part A, 2014, 11, 4087- 4097.

50 M. Tomšiĉ, S. Guillot, L. Sagalowicz, M. E. Leser and O. Glatter, Langmuir, 2009, 25, 9525-9534.

51 O. Okay and W. Oppermann, Macromolecules, 2007, 40, 3378-3387.

52 S. B. Ross-Murphy, J. Rheol., 1995, 39, 1451- 1463.

53 M. Tomšiĉ, F. Prossnig and O. Glatter, J. Colloid Interface Sci., 2008, 322, 41-50.

54 M. Iijima, T. Hatakeyama and H. Hatakeyama, Thermochim. Acta, 2014, 596, 63-69.

55 Y. Xu and L. Li, Polymer, 2005, 46, 7410-7417.

56 Y. Xu, L. Li, P. Zheng, Y. C. Lam and X. Hu, Langmuir, 2004, 20, 6134- 6138.

57 C. Maderuelo, A. Zarzuelo and J. M. Lanao, J. Controlled Release, 2011, 154, 2-19.

58 A. Karewicz, K. Zasada, K. Szczubialka, S. Zapotoczny, R. Lach and M. Nowakowska, Int. J. Pharm., 2010, 385, 163-169.

59 Y. Liang and K. L. Kiick, Biomacromolecules, 2016, 17, 601-614.

60 M. Ullrich, J. Hanuš, J. Dohnal and F. Štěpánek, J. Colloid Interface Sci., 2013, 394, 380-385.

61 Y. Liu, Z. Li and D. Liang, Soft Matter, 2012, 8, 4517-4523.

62 T. Mossman, J. Immunol. Methods, 1983, 65, 55-63.

63 M. L. Stephenson and P. C. Zamecnik, Proc. Natl. Acad. Sci. U. S. A., 1978, 75, 285- 288.

64 H.-Y. Zhang, J. Mao, D. Zhou, Y. Xu, H. Thonberg, Z. Liang and C. Wahlestedt, Nucleic Acids Res., 2003, 31, e72.

65 A. F. Jorge, R. Röder, P. Kos, R. S. Dias, E. Wagner and A. C. C. Pais, Biochim. Biophys. Acta, 2015, 1850, 1325-1335. 


\section{Electronic Supplementary Material (ESI)}

Cationic Nioplexes-in-Polysaccharide-Based Hydrogels as Biodegradable Hybrid Materials to Deliver Nucleic Acids

Santiago Grijalvo, Adele Alagia, Judith M ayr, Gustavo Puras, Jon Zárate, José Luis Pedraz, Ramon Eritja and David Díaz Díaz 


\section{SUMMARY}

TEM image of nioplexes

Encapsulation efficiencies and rheological parameters

Standard calibration curve

Niosomal release model according to Higuchi equation

Niosomal release model according to Korsmeyer-Peppas' equation

Niosomal release model according to Weibull equation

Niosomal release profiles as a function of log cumulative release versus time.

S5

Dynamic light scattering (DLS) of released nioplexes S6

Cryo-SEM images S6

Flow cytometry analysis 
Figure S1 TEM images of nioplexes at N/P of 14. Original magnification 2500X

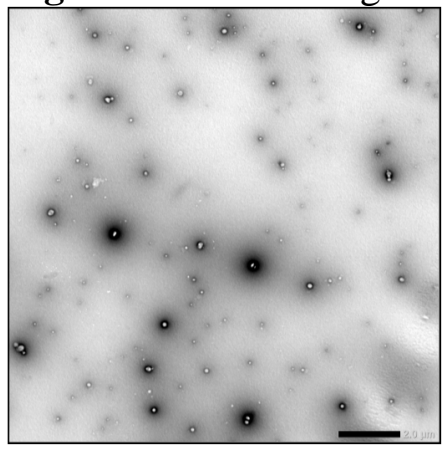

Table S1 Encapsulation efficiencies of cationic nioplexes and rheological parameters for Hydrogel_3 and Hydrogel_4. Native hydrogels (Hydrogel_1 and_2) were used as controls for comparison purposes.

\begin{tabular}{|l|l|l|l|l|l|l|l|l|}
\hline Entry & Polysaccharide $^{\mathrm{a}}$ & Hydrogel & $\begin{array}{l}\text { Entrapped } \\
\text { nioplexes }\end{array}$ & $\begin{array}{l}\mathrm{EE}^{\mathrm{b}} \\
(\%)\end{array}$ & $\begin{array}{l}G^{\prime \mathrm{c}} \\
(\mathrm{kPa})\end{array}$ & $\begin{array}{l}G^{, \mathrm{d}} \\
(\mathrm{kPa})\end{array}$ & $\begin{array}{l}\mathrm{Y}^{\mathrm{e}} \\
(\%)\end{array}$ & $\begin{array}{l}\text { tan } \\
\delta\end{array}$ \\
\hline 1 & $\mathrm{KC}$ & 3 & yes & 95.7 & 36742 & 8757 & 1.1 & 0.13 \\
\hline 2 & $\mathrm{MC}: \mathrm{KC}$ & 4 & yes & 98.4 & 2413 & 535.6 & 41 & 0.16 \\
\hline 3 & $\mathrm{KC}$ & 1 & - & - & 71877 & 11615 & 0.68 & 0.21 \\
\hline 4 & $\mathrm{MC}: \mathrm{KC}$ & 2 & - & - & 1026 & 192 & 3.9 & 0.23 \\
\hline
\end{tabular}

${ }^{a}$ kappa-carrageenan $(\mathrm{KC})(4 \% ; w / v) ; 1: 1$ mixture of methylcellulose:kappa-carrageenan (MC:KC) $(2 \%$, $w / v)$ (in total $4 \% w t$ of polymers); ${ }^{b}$ encapsulation efficiency; ${ }^{c}$ storage modulus; ${ }^{d}$ loss modulus; ${ }^{\mathrm{e}} \mathrm{Y}$ at break

Figure S2 Standard calibration curve

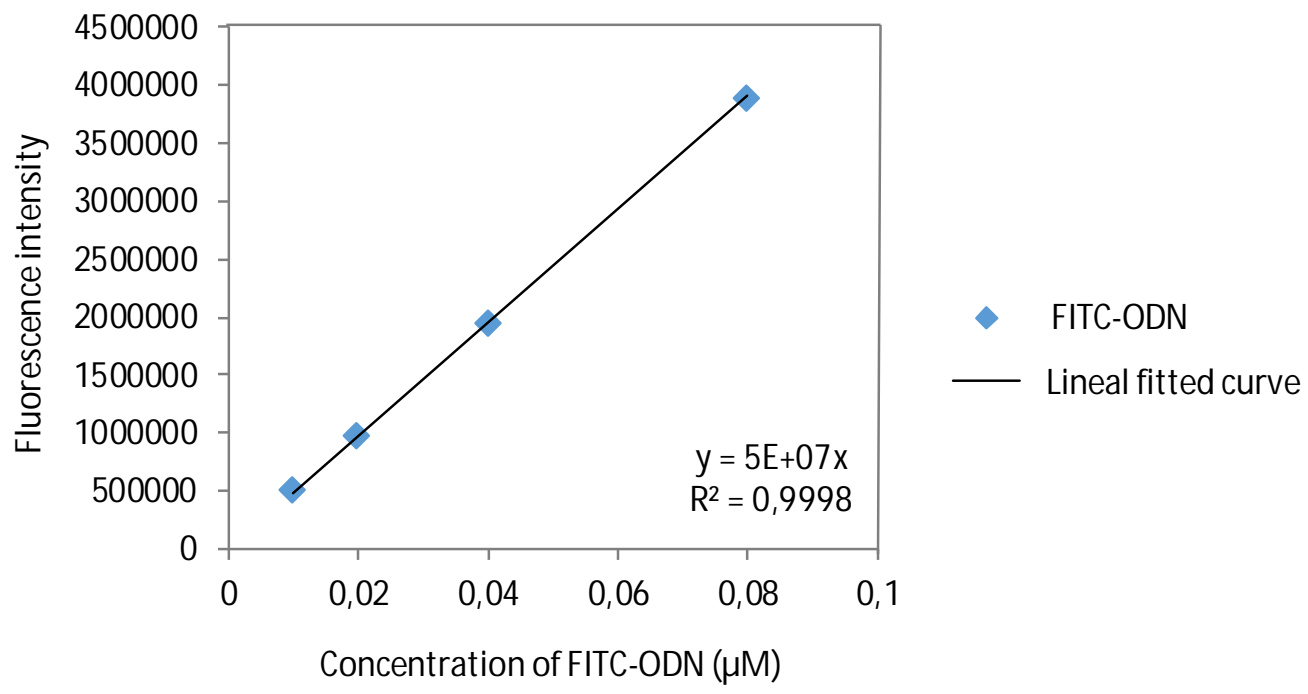


Table S2 Model release parameters for Hydrogel_3 and _4 according to Higuchi equation

$$
\frac{M_{t}}{M_{\infty}}=K * \sqrt{t}
$$

\begin{tabular}{|l|l|l|l|}
\hline Entry & Hydrogel & $k$ & $r^{2}$ \\
\hline 1 & 3 & 3.57 & 0.9947 \\
\hline 2 & 4 & 2.14 & 0.9690 \\
\hline
\end{tabular}

Table S3 Model release parameters for Hydrogel_3 and _4 according to KorsmeyerPeppas' equation. The model was fitted for the first $60 \%$ of the niosomal FITC-ODN release

$$
\frac{M_{t}}{M_{\infty}}=K * t^{n}
$$

\begin{tabular}{|l|l|l|l|l|}
\hline Entry & Hydrogel & $k$ & $n$ & $r^{2}$ \\
\hline 1 & 3 & 2.58 & 0.55 & 0.9994 \\
\hline 2 & 4 & 3.89 & 0.41 & 0.9928 \\
\hline
\end{tabular}

Table S4 Model release parameters for Hydrogel_3 and $4 \mathbf{4}$ according to Weibull equation.

$$
\frac{M_{t}}{M_{\infty}}=\alpha *\left(1-\exp \left(-(k t)^{b}\right)\right)
$$

\begin{tabular}{|l|l|l|l|l|l|}
\hline Entry & Hydrogel & $\alpha$ & $k$ & $b$ & $r^{2}$ \\
\hline 1 & 3 & 561,8 & 0,0021 & 1,051 & 0.9567 \\
\hline 2 & 4 & 104,2 & 0,0011 & 0,58 & 0.9837 \\
\hline
\end{tabular}


Figure S3 Niosomal release profiles of niosomal FITC-ODN from Hydrogels _ 3 and $\mathbf{4}$ according to Korsmeyer-Peppas' equation. The regression coefficient $\left(r^{2}\right)$ for the Korsmeyer-Peppas equation was 0.9994 and 0.9928 for Hydrogel_3 and _4, respectively (using the first $60 \%$ of niosomal release). On the contrary, $r^{2}$ values were lower when Higuchi equation (0.9947 and 0.9690) and Weibull release model $(0.9567$ and 0.9387 ) were used for Hydrogel_3 and_4, respectively,

Hydrogel_3

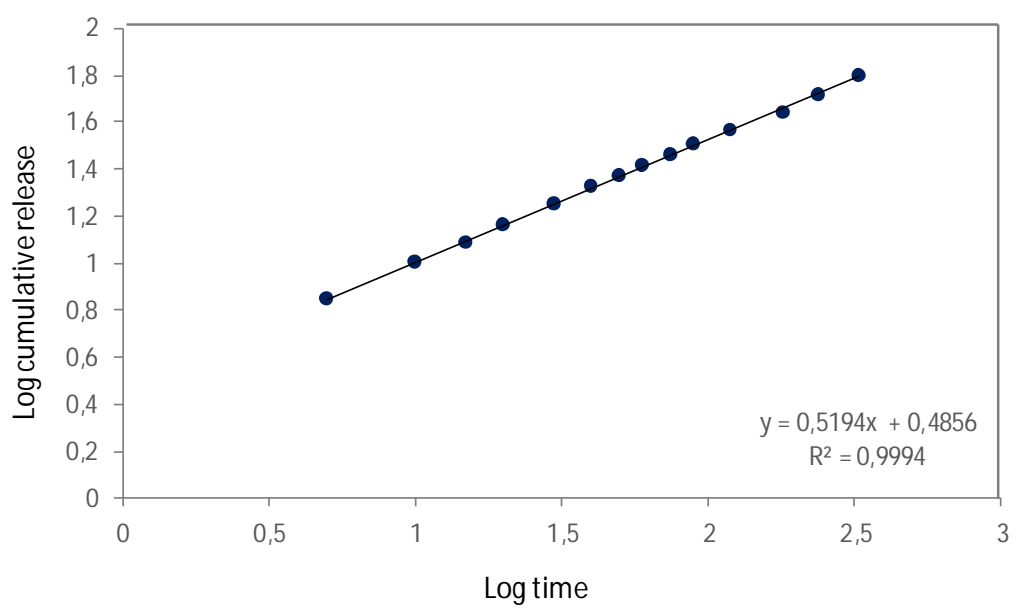

Hydrogel_4

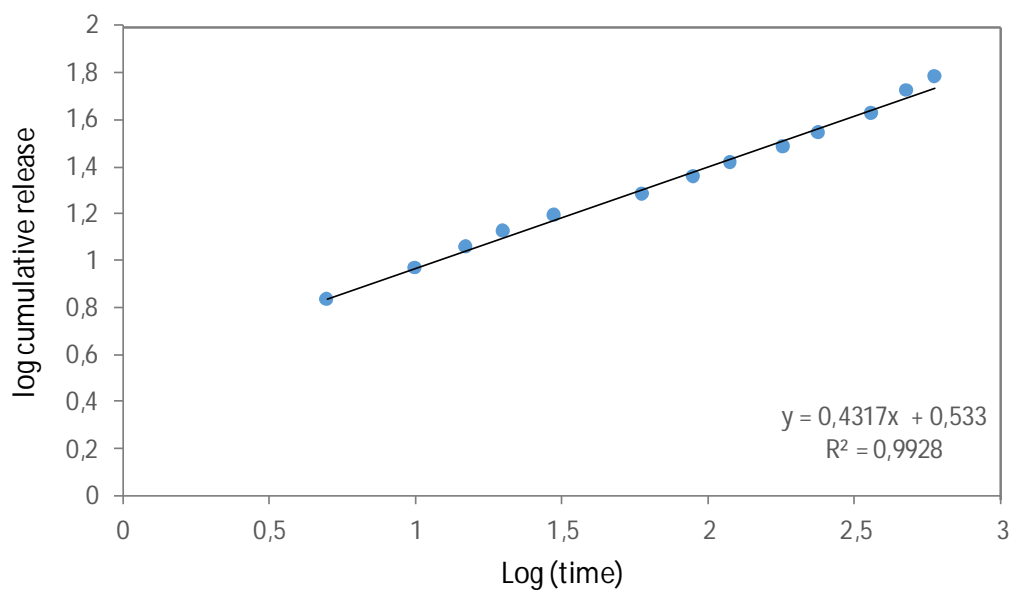


Figure S4 Average hydrodynamic diameter and polydispersity degree of cationic nioplexes after complete KC (Fig. S3A) and MC:KC (Fig. S3B) hydrogels degradation. Hydrodynamic diameter of nioplexes before being encapsulated within $\mathrm{KC}$ and $\mathrm{MC}: \mathrm{KC}$ hydrogels were measured as a control.

A

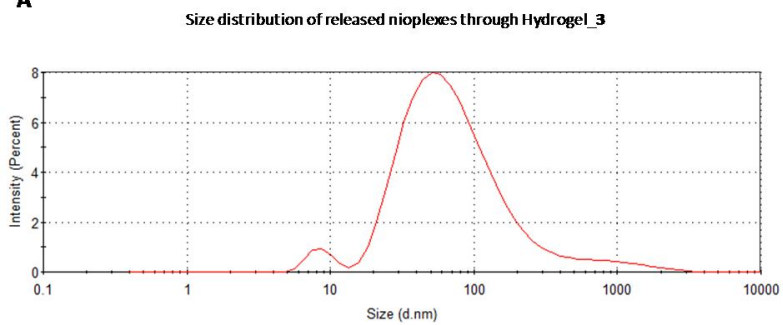

B

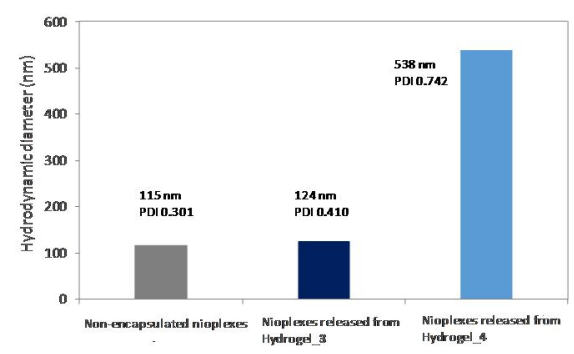

Size distribution of released nioplexes through Hydrogel _

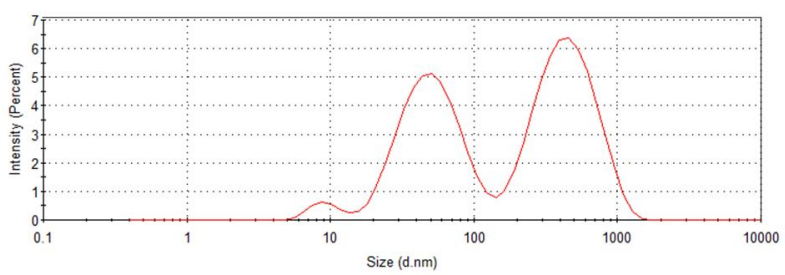

\begin{tabular}{|c|c|c|}
\hline Hydrogel & Diameter size $(\mathrm{nm})$ & PDI \\
\hline 3 & 124 & 0.410 \\
\hline 4 & 538 & 0.742 \\
\hline
\end{tabular}

Figure S5 Cryo-SEM images of A) KC hydrogels (Hydrgel-1) and B) native cationic nioplexes loaded in $\mathrm{KC}$ hydrogels (Hydrogel_3). Cationic nioplexes were obtained using $300 \mathrm{nM}$ of FITC-ODN with a N/P ratio of 14

A

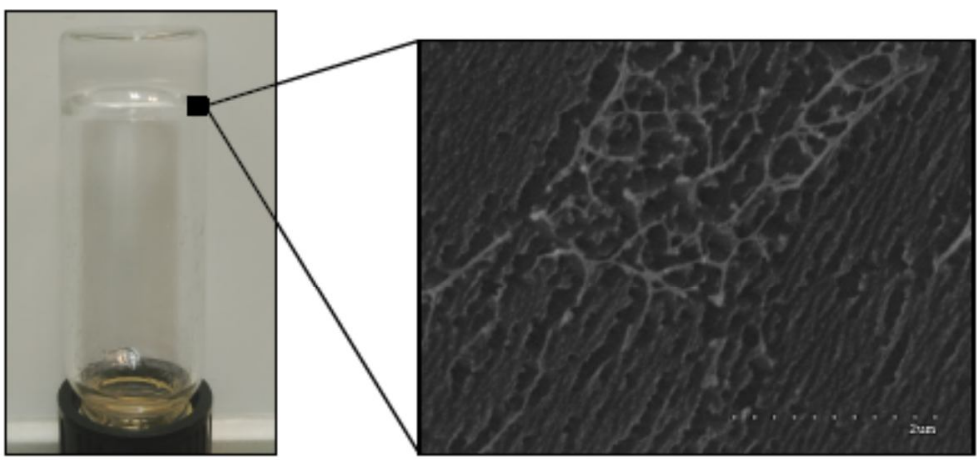

B.1

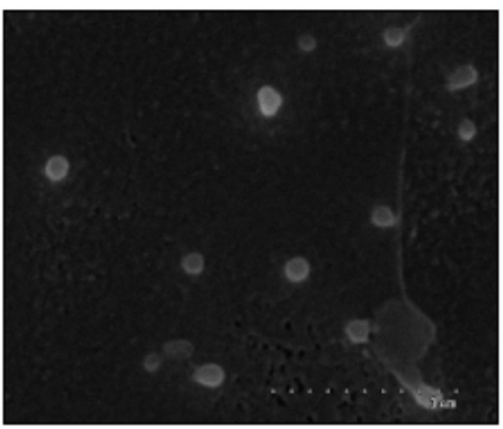

B.2

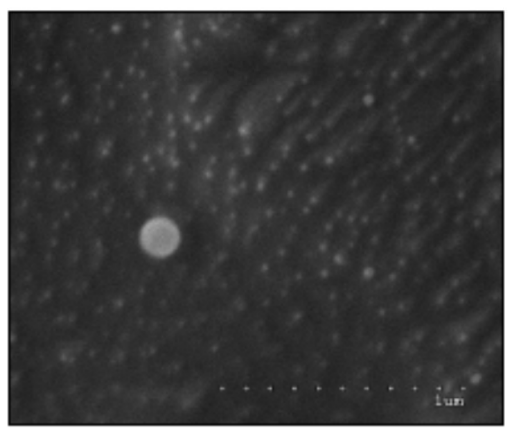


Figure S6 Cryo-SEM images of 1:1 mixture of MC:KC hydrogels (Hydrogel_3)

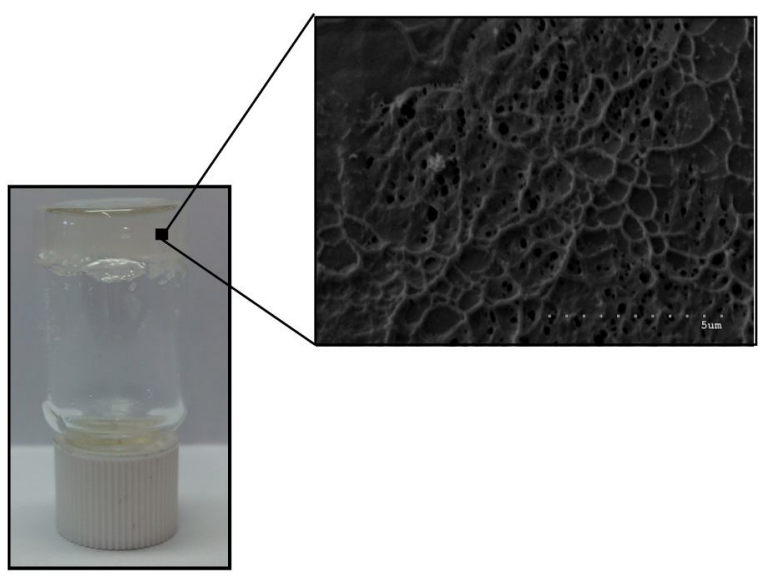

Figure S7 Flow cytometry analysis of HeLa cells treated with pGFP ( formulated in liposomes with lipofectamine
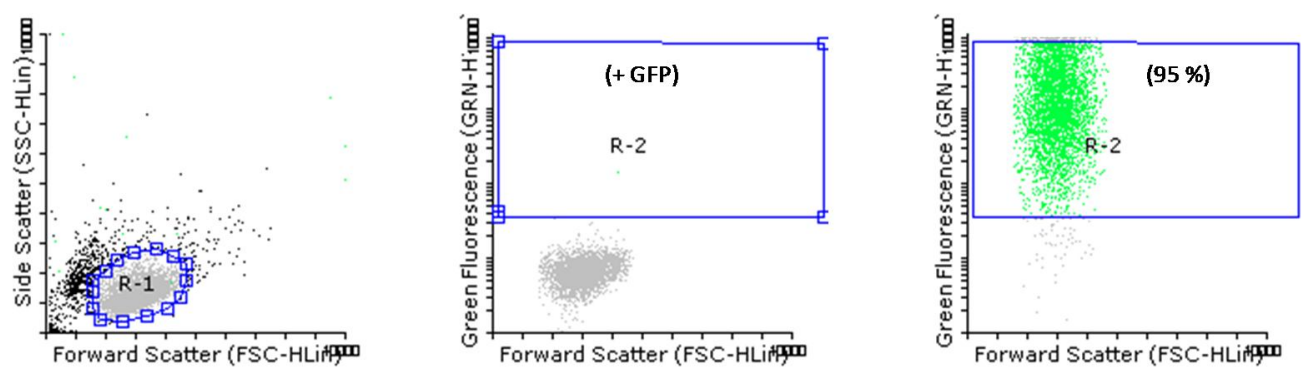

NOTE: NANBIOSIS is one of the 29 Singular Scientific Technological Infrastructures (ICTS) recently recognized by the Spanish Council for Science Policy, Technology and Innovation (MINECO). 